\title{
Recent Advances in Primary and Secondary Prevention of Atherosclerotic Stroke
}

\author{
Georgios Tsivgoulis, ${ }^{\mathrm{a}, \mathrm{b}}$ Apostolos Safouris, ${ }^{\mathrm{a}, \mathrm{c}}$ Dong-Eog Kim, ${ }^{\mathrm{d}}$ Andrei V. Alexandrov ${ }^{\mathrm{b}}$ \\ aSecond Department of Neurology, "Attikon" University Hospital, National and Kapodistrian University of Athens School of Medicine, Athens, \\ Greece \\ bDepartment of Neurology, The University of Tennessee Health Science Center, Memphis, TN, USA \\ 'Stroke Unit, Metropolitan Hospital, Pireus, Greece \\ ${ }^{d}$ Department of Neurology, Dongguk University Ilsan Hospital, Dongguk University College of Medicine, Goyang, Korea
}

Atherosclerosis is a major cause of ischemic stroke that can be effectively prevented with appropriate lifestyle modifications and control of cardiovascular risk factors. Medical advances in recent years along with aggressive cardiovascular risk factor modifications have resulted in decreased recurrence rates of atherosclerotic stroke. Non-statin lipid-lowering molecules have recently shown clinical benefit and are recommended for very high-risk patients to reduce their risk of stroke. Aggressive hypertension treatment is crucial to reduce atherosclerotic stroke risk. Advances in antithrombotic treatments include combinations of antiplatelets and new antiplatelet agents in the acute phase post-stroke, which carries a high risk of recurrence. Intensive medical treatment has also limited the indications for carotid interventions, especially for asymptomatic disease. Intracranial atherosclerotic disease may provoke stroke through various mechanisms; it is increasingly recognized as a cause of ischemic stroke with advanced imaging and is best managed with lifestyle modifications and medical therapy. The diagnostic search for the vulnerable culprit atherosclerotic plaque is an area of intense research, from the level of the intracranial arteries to that of the aortic arch. Ultrasonography and novel magnetic resonance imaging techniques (high-resolution vessel-wall imaging) may assist in the identification of vulnerable atherosclerotic plaques as the underlying cause in cryptogenic or misdiagnosed non-atherosclerotic ischemic stroke. Vertebrobasilar atherosclerotic disease is less common than carotid artery disease; thus, high-quality data on effective prevention strategies are scarcer. However, aggressive medical treatment is also the gold standard to reduce cerebrovascular disease located in posterior circulation.

Keywords Atherosclerotic stroke; Hypertension; Dyslipidemia; Extracranial; Intracranial; Atherosclerosis
Correspondence: Georgios Tsivgoulis Second Department of Neurology, "Attikon" University Hospital, National and Kapodistrian University of Athens School of Medicine, Iras 39, Gerakas Attikis, Athens 15344, Greece Tel: $+30-6937178635$

Fax: +30-2105832471 E-mail: tsivgoulisgiorg@yahoo.gr

Received: March 13, 2018

Revised: May 13, 2018

Accepted: May 23, 2018

\section{Introduction}

Atherosclerotic disease involving stenotic and non-stenotic atherosclerotic plaques of the extracranial and intracranial cerebral arteries as well as the aortic arch is a major cause of ischemic stroke. Regardless of the location of the culprit atherosclerotic plaque, atherosclerosis is a systemic disease affecting the brain, the heart, the aorta, the peripheral vessels, and the kidneys. As a result, atherosclerotic risk factors and interventions to reduce atherosclerotic vascular disease are com- 
mon regardless of the end organ. Atherosclerosis starts at an early age with the deposition of foam cells in the intima, leading to fatty streaks that will eventually progress to atherosclerotic plaques through the deleterious effects of multiple vascular risk factors. ${ }^{1}$ Physical inactivity, obesity, and unhealthy diet can lead to dyslipidemia, which is a major driving force of atherosclerosis. ${ }^{2}$ Hypertension and diabetes damage the endothelium and accelerate atherosclerosis. ${ }^{3}$

Major recent breakthroughs in atherosclerotic disease prevention and treatment in diverse fields of medical science are critical to stroke physicians for the optimal treatment of atherosclerotic stroke patients. Ten potentially modifiable risk factors (hypertension, regular physical activity, dyslipidemia, diet, obesity, psychosocial factors, smoking, cardiac causes, alcohol consumption, and diabetes mellitus) account for $90 \%$ of the population attributable risks of stroke. ${ }^{4}$ Lifestyle modifications and intensive medical treatment have proven benefits and have evolved considerably in recent years, making the net clinical benefit of surgical or endovascular interventions for extracranial atherosclerotic disease less important. Endovascular interventions for intracranial atherosclerotic disease (ICAD) are currently reserved only for recurrent ischemic strokes despite best medical therapy (BMT).

Exciting results from aggressive cardiovascular risk factor (CVRF) modification studies through BMT promise marked reduction of the risk of atherosclerotic stroke-but at a price that may be prohibitive for individuals or societies of limited resources. On the other hand, measures by healthcare policymakers to implement widespread lifestyle modifications are lowcost interventions for the primary and secondary prevention of atherosclerotic stroke, which could obviate the need for polypharmacy.

The aim of this narrative review is to present recent medical breakthroughs in the primary and secondary prevention of atherosclerotic stroke through lifestyle modifications, novel treatments of modifiable risk factors for atherosclerosis, and optimized antithrombotic treatment, as well as to discuss the current role of interventions for symptomatic and asymptomatic extracranial or intracranial atherosclerotic plaques.

\section{Lifestyle modifications}

The promotion of a healthy lifestyle is the cornerstone for primary and secondary atherosclerotic prevention of stroke. Smoking is an independent risk factor for ischemic stroke, but the excess risk of stroke appears to be reduced 2 to 4 years after smoking cessation. ${ }^{5}$ Physically active individuals have a $25 \%$ to $30 \%$ lower risk of stroke or mortality. ${ }^{6}$ Healthy adults should perform moderate- to vigorous-intensity aerobic physical activity at least $40 \mathrm{~min} /$ day for 4 days/week. Obesity increases the risk of ischemic stroke by $22 \%$ for overweight individuals and 64\% for obese individuals compared with normalweight individuals. ${ }^{7}$ Above a body mass index of $25 \mathrm{~kg} / \mathrm{m}^{2}$, there is a $40 \%$ increased stroke mortality for every $5 \mathrm{~kg} / \mathrm{m}^{2}$ increase in body mass index. ${ }^{8}$

The 2013 lifestyle management guidelines from the American Heart Association (AHA) advocate a dietary pattern that emphasizes the intake of vegetables, fruits, and whole grains and limits the intake of sweets, sugar-sweetened beverages, red meat, saturated fat, and trans-fat. ${ }^{9}$ An energy-unrestricted Mediterranean diet supplemented by nuts (walnuts, hazelnuts, and almonds) or by extra-virgin olive oil reduces stroke risk. ${ }^{10}$ In the recently published Dietary Patterns, Sodium Intake and Blood Pressure (DASH-Sodium) trial, 30 days of a combined DASH+low sodium $(1,150 \mathrm{mg})$ diet, compared with 30 days of a typical "American" non-DASH+high sodium $(3,450 \mathrm{mg})$ diet, dramatically lowered blood pressure (BP) for those with systolic blood pressure (SBP) $\geq 150 \mathrm{~mm} \mathrm{Hg}$ by $21 \mathrm{~mm} \mathrm{Hg}{ }_{i}^{2}$ even normotensive patients witnessed a $5-\mathrm{mm} \mathrm{Hg}$ reduction. Data on community interventions of sodium substitution with potassium have indicated similarly impressive results. ${ }^{11}$ Promoting public awareness and public health initiatives against sodium consumption could be a highly cost-effective strategy for reducing the burden of hypertension and atherosclerosis.

Socioeconomic factors are an important risk factor for cardiovascular disease (CVD) and a major obstacle to implementing lifestyle modifications for stroke prevention. Low-income areas and low individual household incomes were found to be independent predictors of a higher 10-year risk for CVD. ${ }^{12}$ Even in high-income countries that have seen reductions in overall stroke risk in recent years, inequality gaps were not bridged. Lower educational level, low income, and living alone are all associated with an increased risk of stroke recurrence, despite adjustment for CVRFs. ${ }^{13}$

\section{Dyslipidemia}

High levels of cholesterol increase ischemic stroke risk, ${ }_{1}^{14}$ whereas low levels may increase hemorrhagic stroke risk, ${ }_{1}^{15}$ which partly explains the paradox that there is no association between total cholesterol and stroke mortality. ${ }^{16}$ Treatment with statins reduces the risk of stroke in patients with or at high risk for atherosclerosis ${ }^{17}$ by $21 \%$; this risk reduction has been associated with each $1 \mathrm{mmol} / \mathrm{L}(39 \mathrm{mg} / \mathrm{dL})$ decrease of low-density lipoprotein (LDL). ${ }^{18}$ High-intensity statin treatment reduces non-fatal cardiovascular events ${ }^{19}$ and leads to lower 
stroke incidence, even in healthy individuals with $L D L<130$ $\mathrm{mg} / \mathrm{dL}$ and high-sensitivity C-reactive protein levels $>2 \mathrm{mg} / \mathrm{L}^{20}$ Despite initial concerns emerging from the negative association of cholesterol levels and hemorrhagic stroke, statin treatment is no longer considered to increase the incidence of hemorrhagic cerebrovascular adverse events. ${ }^{21}$

The first step in the medical management of dyslipidemia is to estimate total cardiovascular risk using a validated score; most risk estimation systems in use are based on either the Framingham $^{22}$ or the System for Cardiac Operative Risk Evaluation (SCORE) projects. ${ }^{23}$ The 2013 American College of Cardiology (ACC)/AHA guideline on the Assessment of Cardiovascular Risk used the Pooled Cohort Equations derived from racially and geographically diverse cohort studies in order to estimate 10-year risk of atherosclerotic cardiovascular disease (ASCVD). ${ }^{24}$ The guidelines endorsed a previous statement from the AHA and American Stroke Association calling for the inclusion of ischemic stroke in the outcome of interest for CVD risk assessment. ${ }^{25} \mathrm{~A}$ web-based application enabling estimation of 10-year and lifetime risk of ASCVD is available at http://my.americanheart.org/ cvriskcalculator. The major determinant of an individual's CVD risk is clinical ASCVD: acute coronary syndromes or a history of myocardial infarction (MI), stable or unstable angina, coronary or other arterial revascularization, stroke, transient ischemic attack (TIA), or peripheral arterial disease (PAD) presumed to be of atherosclerotic origin. ${ }^{26}$

Since the announcement of the aforementioned guidelines, two randomized controlled trials (RCTs) have shown improved CVD outcomes with non-statin lipid-lowering medications: ezetimibe on top of simvastatin ${ }^{27}$ and evocolumab on top of statin therapy. ${ }^{28}$ Guidelines that incorporated these positive findings were published in 2017 and gave specific target LDL levels (Table 1) ${ }_{1}^{29}$ following the approach described in an American expert consensus ${ }^{30}$ and the European guidelines of 2016 . $^{31}$ These guidelines also recommend fibrates for patients with triglycerides $>200 \mathrm{mg} / \mathrm{dL}$ and $\mathrm{HDL}<40 \mathrm{mg} / \mathrm{dL}$. As we are awaiting the 2018 ACC/AHA guidelines, it seems that the updated LDL targets could be of benefit in atherosclerotic stroke patients. ${ }^{32}$ An update on proprotein convertase subtilisin/kexin type 9 (PCSK9) inhibitors has been recently published, which provides guidance for non-statin dyslipidemia treatment in order to attain very low LDL goals. ${ }^{33}$ Add-on ezetimibe therapy may provide a $20 \%$ LDL level reduction, which may be insufficient for very high-risk patients. ${ }^{34}$ PCSK9 inhibitors are recommended for very high-risk patients who-despite statins with or without ezetimibe therapy, or because of an inability to tolerate sufficient doses of at least three statins-do not attain the $L D L$ goal of $<140$ or $<100 \mathrm{mg} / \mathrm{dL}$ for those with rapidly progressive ASCVD or complex multivessel or polyvascular atherosclerotic disease. PCSK9 inhibitors are not indicated for asymptomatic ASCVD patients, except for patients with familial hypercholesterolemia who are at high or very high cardiovascular risk and have not attained LDL goals despite high-intensity statin plus ezetimibe therapy. It remains unclear how these guidelines will be implemented in clinical practice because the individuals eligible for treatment are substantially increased ${ }^{35}$ and the cost-effectiveness of novel agents is hard to prove at the current price point. ${ }^{36}$ When longer-term follow-up clinical data become available, treatment will likely have become costeffective for very high-risk patients.

Unlike coronary heart disease and PAD, ischemic stroke has major non-atherosclerotic causes (cardioembolic and lacunar

Table 1. 2017 American Association of Clinical Endocrinologists and American College of Endocrinology guidelines for the management of dyslipidemia and prevention of cardiovascular disease ${ }^{29}$

\begin{tabular}{|c|c|c|}
\hline Category & Risk factors or 10 -year risk of ASCVD* & LDL targets (mg/dL) \\
\hline Extreme risk & $\begin{array}{l}\text { 1. Progressive ASCVD despite } L D L<70 \mathrm{mg} / \mathrm{dL} \\
\text { 2. Established clinical } A S C V D \text { in patients with } D M, C K D 3 / 4 \text {, or heterozygous familial hypercholesterolemia } \\
\text { 3. History of premature ASCVD ( }<55 \text { years for males, }<65 \text { years for females) }\end{array}$ & $<55$ \\
\hline Very high risk & $\begin{array}{l}\text { 1. Established or recent hospitalization for acute coronary syndrome, coronary, carotid, or peripheral vascular dis- } \\
\text { ease, } 10 \text {-year risk }>20 \% \\
\text { 2. Diabetes or chronic kidney disease stages } 3 / 4 \text { with } 1 \text { or more risk factor(s) } \\
\text { 3. Heterozygous familial hypercholesterolemia }\end{array}$ & $<70$ \\
\hline High risk & $\begin{array}{l}\text { 1. } \geq 2 \text { Risk factors and } 10 \text {-year risk } 10 \%-20 \% \\
\text { 2. DM or chronic kidney disease stages } 3 / 4\end{array}$ & $<100$ \\
\hline Moderate risk & $\leq 2$ Risk factors and 10 -year risk $<10 \%$ & $<100$ \\
\hline Low risk & No risk factors & $<130$ \\
\hline
\end{tabular}

Major independent risk factors besides elevated LDL are polycystic ovary syndrome, cigarette smoking, hypertension, high-density lipoprotein (HDL) $<40 \mathrm{mg} / \mathrm{dL}$, family history of coronary artery disease, CKD stage $3 / 4$, evidence of coronary artery calcification in men $\geq 45$ years or in women $\geq 55$ years. Subtract 1 risk factor if $\mathrm{HDL}>60 \mathrm{mg} / \mathrm{dL}$.

ASCVD, atherosclerotic cardiovascular disease; LDL, low-density lipoprotein; DM, diabetes mellitus; CKD, chronic kidney disease.

${ }^{*}$ Defined as defined as nonfatal MI, coronary heart disease death, nonfatal and fatal stroke. 
strokes). Therefore, it is sometimes challenging to prove etiology and leads to a high percentage of cryptogenic strokes despite extensive work-up, as will be discussed later in this article. In the seminal Stroke Prevention by Aggressive Reduction in Cholesterol Levels (SPARCL) study, the use of a high-intensity statin (80 $\mathrm{mg}$ of atorvastatin) for non-cardioembolic stroke/ TIA patients without concomitant CVD led to reduced risk of fatal recurrent stroke by $43 \%$ and any cardiovascular event by $26 \%,{ }^{37}$ proving that treatment of atherosclerosis in non-cardioembolic ischemic stroke has beneficial clinical implications. Stroke survivors had a 5 -year vascular event risk of 17\%, which is comparable to that of coronary risk equivalents. Even in the lowest risk group of 40- to 70-year-olds without coronary artery disease, the 5 -year risk of $\mathrm{Ml}$ or vascular death was $10 \%{ }^{38}$

Atrial fibrillation (AF), the main cause of cardioembolic stroke, is also an independent predictor of $\mathrm{Ml}$ or vascular event in stroke survivors. Recent research shows that AF patients with concomitant vascular disease are severely undertreated for vascular disease. ${ }^{39}$ It should be kept in mind that the items included in the $\mathrm{CHA}_{2} \mathrm{DS}_{2}$-VASc score (used to calculate embolic risk in AF patients) are clinical expressions or risk factors of atherosclerotic vascular disease.

Consequently, comprehensive management of ischemic stroke patients should include implementation of the current guidelines for atherosclerotic vascular disease because they severely affect long-term outcomes. Using statin treatment guidelines for "presumably atherosclerotic" ischemic stroke patients means treating most stroke patients with high-dose statins (80 $\mathrm{mg}$ atorvastatin or $40 \mathrm{mg}$ of rosuvastatin)-a practice supported by the highest quality evidence avaliable for statin treatment in secondary stroke prevention, the SPARCL trial. It should be noted that recurrent strokes during the SPARCL trial also tended to be less severe for patients on statins, a finding that has been since replicated. ${ }^{40}$ Patients with atherosclerotic stroke pretreated with statins have greater neurological improvement 1 month later. ${ }^{41}$ Patients who are pretreated with statins have lower prevalence of microembolic signals (MESs) on transcranial Doppler (TCD) monitoring, and the relationship between MES burden and statin pretreatment appears to be dose dependent. ${ }^{42}$

\section{Hypertension}

Hypertension is a major risk factor for both ischemic and hemorrhagic stroke. Whereas hypertension is strongly linked to smallvessel cerebrovascular disease such as lipohyalinosis-related lacunar infarction, it is also a major cause of atherosclerotic stroke. ${ }^{43}$ Throughout the range of BP, including normotensive values, a higher BP is associated with a greater risk of stroke. ${ }^{44}$ Mean BP levels of 133/76 mm Hg, compared with 140/81 mm $\mathrm{Hg}$, were associated with a reduction in risk of stroke by $22 \%$ in a meta-analysis of primary and secondary prevention studies. ${ }^{45}$ The effect is even greater (at 27\%) when only secondary prevention studies are considered: both SBP and diastolic BP reduction are linearly related to the lower risk of recurrent stroke, and aggressive BP control to a target of $<130 \mathrm{~mm} \mathrm{Hg}$ seems to be effective for secondary stroke prevention. ${ }^{46}$

Recent guidelines have confirmed the importance of strict BP control and eliminated the term "pre-hypertension" by lowering normal BP levels to $<120 / 80 \mathrm{~mm} \mathrm{Hg.}{ }^{47} \mathrm{BP}$ ranging from 130/80 to $140 / 90 \mathrm{~mm} \mathrm{Hg}$ is now considered stage 1 hypertension and should be treated in all symptomatic ASCVD individuals and asymptomatic individuals with 10-year ASCVD risk over 10\%; an exception is only made for secondary stroke prevention, for which the cutoff for antihypertensive treatment initiation of $140 / 90 \mathrm{~mm} \mathrm{Hg}$ is maintained, but the BP goal for those treated remains at 130/80 $\mathrm{mm} \mathrm{Hg}$. The higher cutoff proposed for secondary stroke prevention is based on multiple observations that very low BP may harm stroke patients. A lower SBP target $(<130$ $\mathrm{mm} \mathrm{Hg}$ ) is recommended only after lacunar stroke; however, even in this context, the benefit seems to be derived from a reduced risk for hemorrhagic but not ischemic stroke. ${ }^{48}$ SBP of $>140 \mathrm{~mm} \mathrm{Hg}$ in symptomatic patients with intracranial stenosis is associated with an increased risk of stroke; ${ }^{49}$ however, low diastolic BP may be deleterious, especially when accompanied by increased pulse pressure of $>60 \mathrm{~mm} \mathrm{Hg.}{ }^{50}$ In a post hoc analysis of the Prevention Regimen for Effectively Avoiding Second Strokes (PROFESS) trial, low BP in patients after non-cardioembolic stroke was associated with worse outcomes; however, it could not be discerned whether low BP was causal or simply an indicator of poor health status. ${ }^{51}$

\section{Diabetes mellitus}

Diabetic patients are at risk for both lacunar stroke ${ }^{52}$ and largeartery stroke. ${ }^{53}$ Diabetes may accelerate atheromatosis by inflammatory pathways through the production of free radicals and inhibition of nitric oxide synthase, exposing the endothelium to shear stress. ${ }^{54} \mathrm{~A} 10$-year duration of diabetes mellitus triples the risk for stroke, while one in five patients with diabetes mellitus will die of stroke. ${ }^{55}$ Diabetic patients have both a high prevalence of CVRF and increased susceptibility to atherosclerosis. Lifestyle modifications and pharmacotherapy aim to accomplish glycemic control with a target glycated hemoglobin of $<6.5 \%$ for most patients, while achieving lipid and BP targets is important for reducing ASCVD risk for patients with 
diabetes or prediabetes. ${ }^{56}$ The Action to Control Cardiovascular Risk in Diabetes Blood Pressure (ACCORD BP) trial has demonstrated that intensive BP control (i.e., target SBP of $<120 \mathrm{~mm}$ $\mathrm{Hg}$ as opposed to $<140 \mathrm{~mm} \mathrm{Hg}$ ) reduces stroke risk by $41 \%$ in diabetic patients at increased ASCVD risk, at the expense of an increased risk of renal insufficiency (number needed to harm $=50) .{ }^{57}$ Aspirin should be taken by diabetic patients at high risk of ASCVD for the primary prevention of CVD, although it is unclear whether it contributes to primary stroke prevention; ${ }^{.58}$ there is also an ongoing debate whether diabetic patients need a greater dose of aspirin because of an increased prevalence of resistance to aspirin. ${ }^{59}$

Metformin remains the first-line treatment for type 2 diabetes mellitus patients according to guidelines, and metformin has a potential benefit for patients with clinical atherosclerotic disease. ${ }^{60}$ When appropriate, diabetic patients with atherosclerotic stroke should also receive oral therapy with agents that have proven significant reduction in atherosclerotic vascular events in clinical trials. These agents are two sodium-glucose cotransporter 2 (SGLT2) inhibitors (empagliflozin ${ }^{61}$ and canagliflozin ${ }^{62}$ ) and one glucagon-like peptide 1 (GLP-1) receptor agonist (liraglutide ${ }^{63}$ ), as well as one thiazolidinedione (pioglitazone ${ }^{64}$ ) that has also shown reduction in the progression of carotid atherosclerosis. ${ }^{65}$

\section{Antiplatelet therapy}

Although anticoagulation remains the mainstay of thromboprophylaxis in cardioembolic stroke, antiplatelets are the preferred antithrombotic treatment for primary and secondary prevention of atherosclerotic stroke, even if the borders are becoming nuanced in most recent clinical research, as will be discussed later. Initiation of aspirin within 48 hours after ischemic stroke leads to a significant reduction in recurrence within 2 weeks. ${ }^{66}$ The addition of dipyridamole appears to be slightly more effective ${ }^{67}$ and clopidogrel appears to be equally effective on secondary stroke prevention when compared to aspirin plus dipyridamole. ${ }^{68}$ Clopidogrel has been shown to be slightly more efficacious than aspirin for the composite outcome of ischemic stroke, $\mathrm{Ml}$, or vascular death; ${ }^{69}$ this benefit is more pronounced for patients with polyvascular disease and those with symptomatic atherosclerotic disease..$^{70}$ It could also be an option for secondary stroke prevention after non-cardioembolic ischemic stroke while the patient was on aspirin. ${ }^{71}$

The benefits of long-term treatment with aspirin plus clopidogrel (dual antiplatelet therapy [DAPT]) in patients with acute coronary syndrome were never replicated in stroke patients. Furthermore, DAPT has shown same efficacy but more bleeding complications than aspirin monotherapy ${ }_{i}^{72,73}$ more importantly, long-term DAPT after lacunar strokes is associated with increased mortality. ${ }^{74} \mathrm{~A}$ Chinese study has shown that a 90-day regimen of DAPT after TIA or minor stroke reduces risk of recurrence. ${ }^{75}$ A reduction of major ischemic events (with most of the prevented events being ischemic strokes) with DAPT has been replicated in Western populations. However, patients on DAPT also showed a higher risk of major hemorrhage (namely extracranial) at 90 days than those who received aspirin alone. ${ }^{76}$ Nevertheless, DAPT was beneficial (compared to aspirin monotherapy) in reducing the composite endpoint of ischemic stroke, Ml, or death from ischemic vascular causes, as well as the composite endpoint of ischemic and hemorrhagic stroke. Notably, secondary analysis of the results revealed that prevention of ischemic outcomes with DAPT was significant throughout the first 7 to 30 days of treatment, whereas the risk of major hemorrhage became greater only during the period from 8 to 90 days. For every 1,000 patients treated with DAPT, a total of 15 ischemic events would be prevented and five major hemorrhages would occur.

In patients with ischemic stroke or TIA with potentially symptomatic atherosclerotic stenosis of ipsilateral intracranial or extracranial arteries, ticagrelor plus aspirin reduced stroke recurrence compared to aspirin alone. A composite vascular endpoint (i.e., stroke, $\mathrm{Ml}$, or vascular death) occurred within 90 days for $6.7 \%$ of patients treated with ticagrelor, which was significantly less than the $9.6 \%$ in the aspirin arm of the trial. ${ }^{77}$ It is worth mentioning that no difference of vascular endpoints was noted in patients without lacunar stroke, highlighting the fact that secondary thromboprophylaxis for atherosclerotic stroke should be studied in dedicated trials and that aggressive antiplatelet treatment seems to be a valid therapeutic strategy to reduce residual recurrence risk in atherosclerotic stroke patients. Another antiplatelet drug, cilostazol, ${ }^{78-80}$ was found to be non-inferior to aspirin in a recent clinical trial for the prevention of cardiovascular events (the composite of stroke, Ml, or vascular death) in Asian patients who had ischemic stroke with a history of or imaging findings of intracerebral hemorrhage or two or more microbleeds; however, it did not reduce hemorrhagic events. ${ }^{81}$ In an open-label part of the same trial, the addition of probucol to aspirin or cilostazol seemed to reduce the incidence of cardiovascular events.

\section{Anticoagulation therapy}

Apart from the positive results with aggressive antiplatelet therapy (either DAPT or ticagrelor), a breakthrough in 2017 was the publication of the Cardiovascular Outcomes for People Us- 
ing Anticoagulation Strategies (COMPASS) trial. For the first time, a combination of an anticoagulant ( $2.5 \mathrm{mg}$ of rivaroxaban twice a day) and aspirin was proven superior both to aspirin alone and to $5 \mathrm{mg}$ of rivaroxaban twice a day in stable atherosclerotic disease. ${ }^{82}$ This study included patients with different expressions of atherosclerosis: coronary, peripheral, and carotid artery disease that was either symptomatic (after intervention) or asymptomatic ( $>50 \%$ stenosis). A composite outcome of ischemic and hemorrhagic events was significantly in favor of patients in the combined treatment group. What is even more exciting is the fact that efficacy outcomes were mainly driven by a $50 \%$ relative risk reduction in ischemic stroke risk $(P<0.001)$.

It should be stressed that a significant reduction in mortality was noted with a twice-daily 2.5-mg dose of rivaroxaban, as seen in a previous trial on acute coronary syndrome in which a twice-daily 2.5-mg dose of rivaroxaban on top of DAPT was superior to DAPT alone or DAPT plus a twice-daily 5-mg dose of rivaroxaban. ${ }^{83}$ However, more bleeding was noted in the combined treatment group, even if fatal and intracranial bleeding were not significantly different. Therefore, rivaroxaban plus aspirin should be used with caution in patients who are at risk of bleeding, such as older patients and those with a history of gastrointestinal bleeding, taking into consideration the higher risk for gastrointestinal bleeding in AF-anticoagulation doses of rivaroxaban. ${ }^{84}$ However, we could soon witness a very important change in the treatment guidelines on the secondary prevention of atherosclerotic stroke with the addition of twicedaily low-dose rivaroxaban to aspirin, changing the decadesold paradigm of antiplatelet therapy. ${ }^{85}$

\section{Anti-inflammatory therapy}

Inflammation in atherosclerosis is an emerging therapeutic target. Data have shown that carotid plaque ${ }^{18} \mathrm{~F}$-fluorodeoxyglucose $\left({ }^{18} \mathrm{~F}-\mathrm{FDG}\right)$ uptake is an independent predictor of early stroke recurrence in patients with recently symptomatic carotid stenosis. ${ }^{86}$ In the Canakinumab Antiinflammatory Thrombosis Outcome Study (CANTOS), canakinumab (a human monoclonal antibody against interleukin-1 $\beta$ ) at a dose of $150 \mathrm{mg}$ every 3 months was shown to reduce incidence of the composite outcome of non-fatal MI, non-fatal stroke, and cardiovascular death in patients after Ml who had increased levels of highsensitivity C-reactive protein. ${ }^{87}$ Hematologic side effects included neutropenia and thrombocytopenia; patients in the treatment arm also had increased risk for fatal infections. Mortality was equal in both arms because the patients on treatment had unexpectedly lower cancer-related death rates. The main limitation for clinical implementation is the vertiginous annual cost of treatment at 200,000 USD. ${ }^{88}$

On the contrary, colchicine is a low-cost anti-inflammatory drug that does not carry a risk for fatal infections. Low-dose colchicine reduces the composite incidence of acute coronary syndrome, out-of-hospital cardiac arrest, or non-cardioembolic ischemic stroke in patients with stable coronary artery disease. ${ }^{89}$ Colchicine could prove to have a significant role to play in plaque stabilization; ${ }^{90}$ an $\mathrm{RCT}$ is ongoing. ${ }^{91}$

\section{Symptomatic extracranial carotid disease}

There is robust evidence that carotid endarterectomy (CEA) or carotid artery stenting (CAS) of symptomatic internal carotid stenosis (ICA) of $>70 \%$ on top of BMT is beneficial in the first 2 weeks after an ipsilateral non-disabling stroke or TIA with a number needed to treat (NNT) of 6 to prevent one major stroke at 2 years. ${ }^{92}$ For patients older than 70 years, CEA seems to be preferable to stenting (Figure 1) $\cdot{ }^{93} \mathrm{~A}$ recently published pooled analysis of RCTs showed that CAS carries a significantly higher periprocedural risk compared to CEA, especially when the intervention is performed in the first 2 weeks following the index
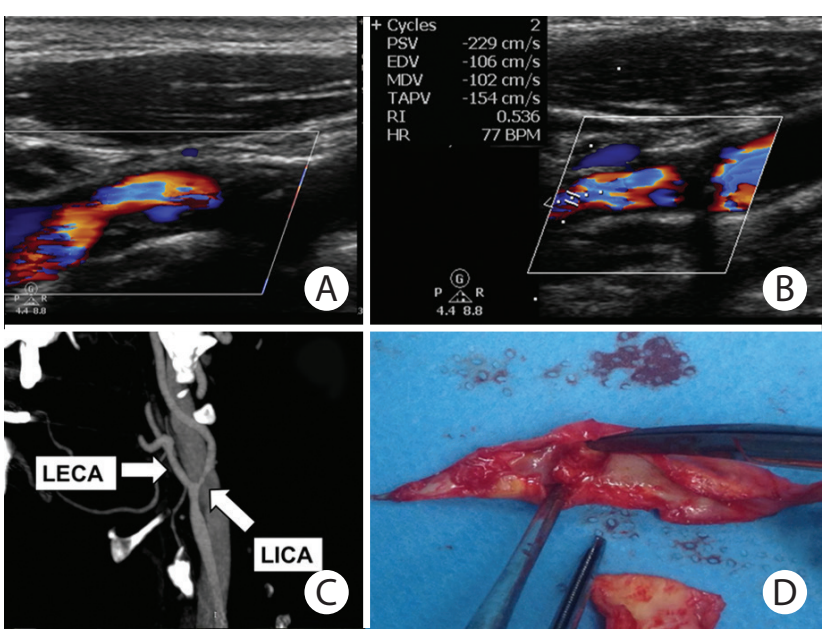

Figure 1. Symptomatic extracranial internal carotid artery (ICA) atherosclerotic plaque: $(\mathrm{A}, \mathrm{B})$ ultrasound imaging, $(\mathrm{C})$ computed tomography $(\mathrm{CT})$ angiography, and (D) pathology specimen. A 52-year-old male smoker with history of hypertension presented with transient aphasia and right hemiparesis lasting for 24 minutes. He reported two similar transient episodes of neurological dysfunction during the last week lasting $<10$ minutes. Brain CT was normal. Carotid duplex showed a heterogeneous mostly hypoechogenic plaque causing a hemodynamically significant $(>70 \%)$ stenosis of the left ICA (peak systolic velocity $229 \mathrm{~cm} / \mathrm{sec}$, end diastolic velocity $106 \mathrm{~cm} / \mathrm{sec}$, ICA/ common carotid artery [CCA] peak systolic velocity ratio 4.4). Ultrasound findings were confirmed on CT angiography. The patient received loading dose of clopidogrel $(300 \mathrm{mg})$ and aspirin $(100 \mathrm{mg}$ ) and underwent uneventfully carotid endarterectomy the next day of his hospital admission. He was discharged with no residual neurological symptoms on the fifth day of ictus. 
event. ${ }^{94}$ This is exactly the time window of opportunity to maximize the benefit from intervention. However, postponing the intervention for 48 hours may be prudent, as there are concerns that ultra-early intervention during the first 2 days after the index event may carry increased risk. ${ }^{95}$ There is a strong case for DAPT in the time interval between stroke and intervention, as clopidogrel load on top of aspirin therapy leads to emboli reduction ${ }^{96}$ as measured by TCD and reduces recurrence by $40 \%$ with an excess of minor bleeding complications related to surgery. ${ }^{97}$

The benefits from intervention diminish rapidly with time. Especially in women, no benefit was found when intervention was delayed more than 2 weeks after randomization. ${ }^{98}$ CAS is a therapeutic alternative, especially in patients with severe medical comorbidities, challenging anatomy, prior neck operation or irradiation, post-CEA restenosis, or contralateral carotid occlusion. Periprocedural risk for CAS appears to be operator-dependent. ${ }^{99}$ In any case and regardless of treatment modality, current guidelines insist that intervention is indicated only if the perioperative morbidity and mortality risk is estimated to be $<6 \% .{ }^{100}$ The benefit-to-risk ratio is much less favorable for women; ${ }^{; 01}$ sex-specific consensus states that perioperative risk should be $<4 \%$ for women undergoing intervention in order to have robust clinical benefit. ${ }^{102}$ It is obvious that this complication rate cutoff is low, but it is far from negligible. Given the fact that BMT has greatly evolved since the RCTs for CEA and CAS, conservative treatment has re-emerged as a valid option even in this high-risk patient group, especially for women, patients younger than 75 years, and cases in which intervention cannot be offered within 2 weeks of the index event. ${ }^{103}$

Benefit is much less important after revascularization of a moderate (50\% to $69 \%$ ) symptomatic ICA stenosis. A total of 15 patients with moderate symptomatic ICA stenosis need to undergo CEA to prevent one ipsilateral stroke during a 5-year period. ${ }^{104}$ It should be kept in mind that the aforementioned NNT is derived from a clinical trial that was conducted decades ago, when hypertension and dyslipidemia were less optimally treated compared to current clinical practice. On the other hand, technical advances in carotid interventions are numerous but have not shown a proven reduction in perioperative risk. ${ }^{105}$ A reduction in perioperative risk in recent trials (going down to 1.4\% in the Carotid Revascularization Endarterectomy Versus Stenting Trial [CREST]) ${ }^{106}$ could be partially explained by the improvement of BMT that is always integrated in the intervention arm, especially statin treatment. Imaging findings that correlated with vulnerable plaques, which are found in patients who are presumably more likely to benefit from intervention, have shown that indices of plaque inflammation on ${ }^{18} \mathrm{~F}-\mathrm{FDG}$ positron-emission tomography (PET)/computed tomography (CT) and high-resolution magnetic resonance imaging (HRMRI) were independent predictors of stroke recurrence. ${ }^{107} \mathrm{Fu}-$ ture studies including molecular imaging research ${ }^{108}$ could identify high-risk groups who would be the most appropriate candidates for intervention. For the time being, intervention can be still justified in most patients with low predicted perioperative risk, especially males. Age could be used as a criterion for selecting the intervention type, because CEA seems to be more beneficial for patients older than 70 years. ${ }^{109}$

\section{Asymptomatic extracranial carotid disease}

In the Framingham Heart Study population, the prevalence of $>50 \%$ ICA stenosis was 7\% in women and $9 \%$ in men older than $65 .{ }^{110}$ Current guidelines state that it is reasonable to perform CEA in asymptomatic patients who have $>70 \%$ ICA stenosis if the risk of perioperative risk is lower than $3 \%$ (class lla; evidence level A) and that CAS might be considered in "highly selected patients" (class Ilb; evidence level B), but at the same time mention that the benefit over BMT is not well established. ${ }^{111}$ It still remains elusive what criteria should be used to identify high-risk patients. There is good evidence that only a minority of patients on BMT for asymptomatic ICA stenosis will benefit from intervention in the current era of intense CVRF management. ${ }^{112}$ Specifically, in 1995, the 5-year risk for ipsilateral stroke was $11 \%,{ }^{113}$ reduced to $5.3 \%$ by $2004^{114}$ and just $3.6 \%$ by $2010,{ }^{115}$ which corresponds to an annual absolute risk of just $0.7 \%$ and to an overall relative risk reduction of $70 \%$ over these 15 years. In contrast to RCTs of symptomatic ICA stenosis, trials of asymptomatic stenosis revealed a limited number of patient characteristics that may predict stroke; for example, ICA occlusion carries a higher risk for stroke only when the contralateral ICA stenosis is symptomatic. ${ }^{116}$ Male sex and age $<75$ years were associated with increased stroke risk. ${ }^{114} \mathrm{~A}$ history of contralateral TIA or stroke appears also to be strongly associated with increased annual stroke risk. ${ }^{117} \mathrm{Si}-$ lent infarcts on brain imaging are also associated with subsequent stroke in asymptomatic ICA stenosis. ${ }^{117}$

Data are still being accumulated to determine whether asymptomatic atherosclerotic plaques should be medically treated. The Objective Randomised Blinded Investigation with Optimal Medical Therapy of Angioplasty in Stable angina (ORBITA) study was published in 2018, which provided class I evidence that percutaneous coronary intervention $(\mathrm{PCl})$ does not increase exercise time in patients with medically treated angina and severe coronary stenosis. ${ }^{118}$ This negative result confirms 
the conclusion of a previous meta-analysis. ${ }^{119}$ Despite the limitation of a small study group and a tendency for improved times in the $\mathrm{PCl}$ arm, it stands in stark contrast to current practice of performing a half-million $\mathrm{PCl}$ procedures for symptomatic relief of stable angina in the United States and Europe each year. ${ }^{120}$ We are witnessing the paradox that good-quality data in favor of interventions comes from acute symptomatic atherosclerosis (carotid or coronary), but interventions in asymptomatic patients with stable atherosclerosis are far more numerous. The problem is much more important than some may think: 92\% of all CEA and CAS in the United States were performed in asymptomatic patients in 2005! ${ }^{121}$ We are not far from having overwhelming evidence that BMT has outraced interventions for primary prevention of atherosclerotic disease. ${ }^{122}$ Thus, there is a good chance we are exposing most asymptomatic atherosclerotic patients to unnecessary risk. ${ }^{123}$ There is an urgent need to pinpoint the minority of asymptomatic patients with vulnerable atherosclerotic plaques that are at risk of provoking symptoms.

It is generally accepted that the main mechanism of stroke in the context of ICA stenosis is artery-to-artery embolism. ${ }^{124}$ Vulnerable plaques that are prone to rupture and cause distal embolism can be detected with ultrasonography. ${ }^{125}$ Plaque composition is assessed on B-mode with ultrasound and can be classified according to echogenicity as types I to V. Plaque surface can be smooth, irregular, or ulcerated. ${ }^{126} \mathrm{~A}$ systematic review reported that plaque angiogenesis, complex plaque morphology, ulceration, echolucent plaques, and intraplaque motion were associated with symptomatic plaques. ${ }^{127}$ There is evidence that heterogeneous plaques comprising of a mixture of hyperechoic, hypoechoic, and isoechoic lesions are significantly more prone to producing symptoms. Patients presenting with vulnerable plaques may be at higher risk for stroke and should be assessed for intervention. The Gray-Scale-Median (GSM) is a computerized measurement of the content of atheromatous plaques, in which low values correspond to hypoechoic plaques. ${ }^{128} \mathrm{~A}$ GSM of $<15$ is associated with a higher stroke risk, but intervention for these plaques also carries a higher periprocedural risk. ${ }^{129}$

Another method of ultrasonography with promising results for selecting high-risk patients is TCD detection of MES. Patients with MES on baseline TCD had an absolute annual risk of stroke ipsilateral to a $>70 \%$ asymptomatic ICA stenosis of $3.7 \%$, whereas patients without MES recording had only $0.7 \%$ annual stroke risk. ${ }^{130}$ Approximately $10 \%$ of screened patients were MES positive; for the other $90 \%$ of patients, negative predictive value was high (94\%), indicating that MES detection is a promising non-invasive technique to select patients at risk of stroke who would benefit from intervention. CT angiography has excellent accuracy for estimating ICA stenosis and is much more sensitive than ultrasonography for detecting plaque ulceration. ${ }^{131}$ Fatty plaques appear hypoattenuated $(<50$ Hounsfield units [HU]), calcified plaques are hyperattenuated $(>120$ $\mathrm{HU})$, and mixed plaques present with intermediate $\mathrm{HU}$ values. ${ }^{132}$ Nevertheless, CT angiography for plaque characterization is limited by its low sensitivity to detect hemorrhage or a lipid core within atheromatous plaques. On the contrary, HRMRI can better depict plaque composition, especially intraplaque hemorrhage (IPH), which seems to be critical marker of plaque instability. IPH has been associated with a three-fold increase in the risk of stroke ipsilateral to ICA stenosis in asymptomatic individuals. ${ }^{133}$

In conclusion, advances in medical treatment have raised questions regarding the benefit of CEA or CAS, especially for moderate symptomatic and asymptomatic ICA stenosis. Three RCTs are currently recruiting patients. ${ }^{134}$ CREST-2 will separately test CEA and CAS for asymptomatic ICA stenosis versus BMT. ${ }^{135}$ Asymptomatic Carotid Surgery Trial 2 (ACST-2) will directly compare CEA to CAS for asymptomatic ICA stenosis. ${ }^{136}$ European Carotid Surgery Trial 2 (ECST-2) will also recruit patients with symptomatic stenosis. ${ }^{137}$ The results of these trials will probably be available after 2020, at which time they will hopefully clarify the role of carotid interventions.

\section{Non-stenotic symptomatic ICA plaques}

In a pooled analysis of RCTs, it has been shown that intervention is of no benefit for symptomatic ICA stenosis of $<50 \%{ }^{92}$ Similarly, according to the Trial of Org 10172 in Acute Stroke Treatment (TOAST) classification, in order for an ischemic stroke to be considered due to large-artery atheromatosis (LAA), the culprit lesion has to cause a stenosis of $>50 \% .{ }^{138} \mathrm{It}$ is clear that there will be atheromatous plaques resulting in $<50 \%$ stenosis that provoke distal embolism. These strokes/ TIAs will be classified as cryptogenic if there is no concomitant stroke cause, but in fact they are missed LAA strokes. It has been suggested that luminal narrowing is not a prerequisite for plaque vulnerability ${ }^{139}$ and it is known that most coronary artery plaques resulting in $\mathrm{MI}$ result in stenosis of $<50 \% .{ }^{140} \mathrm{How}-$ ever, there has been limited availability of imaging techniques to visualize plaque content.

In a seminal study of black-blood MRI examination of the carotid arteries in patients with cryptogenic hemispheric stroke who presented with non-stenotic atherosclerotic plaques thicker than $2 \mathrm{~mm}$ in the carotid bifurcations, AHA type VI plaques (complicated plaques with IPH, thrombus, or rupture of 
the fibrous cap ${ }_{1}^{141}$ known to be overrepresented in symptomatic stenotic ICA plaques ${ }^{142}$ ) were found exclusively on the ipsilateral side of stroke (37.5\% vs. $0.0 \%$ ). ${ }^{143}$ The results were replicated using a routine magnetic resonance (MR) angiography protocol performed on the day of stroke; intraplaque high-intensity signal, a marker of IPH, was once again exclusively found in non-stenotic plaques ipsilateral to the cerebral cryptogenic infarction ( $22 \%$ vs. $0 \%$ ). Non-stenotic plaques of $\geq 5$ $\mathrm{mm}$ thickness on CT angiography were present in 11\% of ipsilateral and $1 \%$ of contralateral arteries in patients with embolic stroke of undetermined source (ESUS); plaques of $\geq 4-\mathrm{mm}$ thickness were present in $19 \%$ and $5 \%$, respectively, and plaques of $\geq 3-\mathrm{mm}$ thickness were present in 35\% and 15\%, respectively. ${ }^{144}$ This important difference of $20 \%$ could correspond to up to one in five ESUS patients having non-stenotic LAA stroke, which would likely not benefit from anticoagulation but would potentially benefit from strict CVRF modification, aggressive short-term antiplatelet therapy, and high-intensity statin treatment. A cross-sectional multicenter carotid MRI study of cryptogenic hemispheric stroke patients, besides revealing high-risk plaque characteristics more frequently on the symptomatic side, found maximal plaque thickness as a strong indicator of high-risk plaque imaging findings. ${ }^{145}$

Carotid MRI in stroke-free participants in the Rotterdam study also reported increased IPH prevalence by quartile of plaque burden. ${ }^{146}$ There have been many reports that challenged the strict TOAST criteria for LAA stroke; in the Causative Classification System of acute ischemic stroke, the term "probable atherosclerotic stroke" has been added. ${ }^{147}$ In the Subtypes of Ischaemic Stroke Classification System, using a total plaque area (TPA) cutoff of $\geq 1.19 \mathrm{~cm}^{2}$ resulted in the detection of $33 \%$ of cases with LAA stroke versus $21 \%$ based on TOAST criteria. ${ }^{148}$ This cutoff has been shown to be associated with a 5-year risk for stroke, death, or MI of 19.5\% after adjustment for multiple risk factors: ${ }^{149}$ interestingly enough, TPA was a stronger predictor of recurrent stroke risk than carotid stenosis. ${ }^{150}$ Finally, a combined high-resolution carotid MRI and ${ }^{18} \mathrm{~F}-\mathrm{FDG}$ PET-apart from confirming once again the presence of AHA type VI lesions ipsilateral to cryptogenic stroke ( $39 \%$ vs. $0 \%, P=0.001)$ revealed that patients harboring at least one type VI lesion showed significantly higher ${ }^{18} \mathrm{~F}-\mathrm{FDG}$ uptake in both carotid arteries, which suggests that atherosclerosis is a diffuse inflammatory process. ${ }^{151}$

\section{Extracranial vertebral disease}

There is evidence that LAA stroke is frequent in the vertebrobasilar circulation. ${ }^{152}$ Ultrasonographic detection of $>50 \%$ ste- nosis in the vertebral arteries is problematic because the origin of the vertebral artery is a common site of stenotic plaques in posterior circulation stroke, ${ }^{.153}$ however, in almost half of patients, it cannot be properly assessed with ultrasonography. ${ }^{154}$ $\mathrm{CT}$ and contrast-enhanced MR angiography both have high sensitivity compared with digital subtraction angiography; CT angiography also presents high specificity. ${ }^{155}$ The Carotid and Vertebral Artery Transluminal Angioplasty Study (CAVATAS) ${ }^{156}$ was the first trial to examine the benefits from stenting stenotic atheromatous lesions; however, it only included 16 patients with posterior circulation. The phase 2 Vertebral Artery Stenting Trial (VAST) randomized 115 patients to either BMT or BMT with stenting. ${ }^{157}$ The risk of stroke in the medically treated group was low, without a significant difference from patients after stenting; however, 5\% of patients suffered from vascular death, $\mathrm{Ml}$, or any stroke within 30 days after intervention. In the Vertebral Artery Ischaemia Stenting Trial (VIST), 182 posterior circulation stroke patients were randomized to either BMT plus stenting or BMT; despite the fact that there were no periprocedural complications with extracranial vertebral artery stenting, very low recurrence rates of posterior circulation stroke under BMT precluded any significant benefit from intervention. ${ }^{158}$ Vertebral intervention should thus be reserved only for those rare cases of recurrence despite BMT. ${ }^{100}$

As opposed to LAA strokes in the anterior circulation, little is known about the risk stratification for recurrence in patients after vertebrobasilar stroke/TIA. A prospective observational trial evaluated distal blood flow compromise as measured by large-vessel quantitative MR angiography in patients with LAA stroke/TIA of the posterior circulation. ${ }^{159}$ Low distal flow status was found in 25\% of patients and was associated with an increased risk for vertebrobasilar stroke recurrence compared to patients with normal distal flow. ${ }^{160}$ This low distal flow group appears to be at particularly high risk for recurrence when $\mathrm{BP}$ is $<140 / 90 \mathrm{~mm} \mathrm{Hg}$; this is an important finding that needs further research because one of the major components of BMT for LAA stroke patients is strict hypertension control. ${ }^{161}$ Nevertheless, it would be premature to discuss permissive hypertension for these patients because this approach has already been tried in stroke patients with intracranial stenosis, for whom mean SBP of $\geq 140 \mathrm{~mm} \mathrm{Hg}$ led to higher rates of stroke, $\mathrm{Ml}$, and vascular death. ${ }^{162}$

\section{Aortic atherosclerosis}

The association between complex (thickness $>4 \mathrm{~mm}$, presence of ulcers or mobile components, lack of calcification) ${ }^{163}$ atheromatous plaques of the aortic arch and stroke has been de- 
scribed in autopsy, ${ }^{164}$ case-control, ${ }_{1}^{165}$ and prospective studies. ${ }^{166}$ MES on TCD are frequent in complex aortic atheromatous plaques. ${ }^{167}$ Some studies have challenged the causal link between aortic atheroma and stroke, asserting that aortic plaques are no more than a marker of generalized atherosclerosis ${ }^{168}$ or fortuitous findings. ${ }^{169}$ On the contrary, studies have also incriminated the descending aorta for harboring atheromatous plaques that may provoke brain embolisms via retrograde diastolic flow as seen on multidirectional three-dimensional (3D) $\mathrm{MRI}$ velocity mapping. ${ }^{170}$ In addition, a higher prevalence of descending aorta complex plaques has been reported with cryptogenic stroke, suggesting an etiopathogenic link. ${ }^{171}$

A systematic review of transesophageal echocardiography (TEE) studies found no association between aortic arch atherosclerosis and cryptogenic stroke. ${ }^{172}$ However, TEE may yield a lower number of plaques in the aortic arch compared both to CT angiography ${ }^{173}$ and 3D MRI. ${ }^{174}$ Additional studies are necessary to prove that descending aorta atherosclerotic plaques can actually provoke brain embolism, especially when they are complex in the distal aortic arch and the proximal segment of descending aorta, where retrograde diastolic flow to brain arteries is maximal. ${ }^{175}$ As for every site of atherosclerosis, statin therapy is crucial for aortic plaque regression ${ }^{176}$ and inflammation reduction. ${ }^{177}$

\section{Intracranial atherosclerotic disease}

ICAD is another expression of systemic atherosclerosis, although, until recently, its importance has been underscored compared with extracranial atherosclerotic disease. However, ICAD is a frequent cause of stroke and merits dedicated study because it differs from extracranial atherosclerosis. First of all, ICAD is more prevalent in Asian populations, but it remains unclear whether the cause is genetic or environmental. ${ }^{178}$ The role of the environment seems to gain in importance because recent studies have reported that the westernization of lifestyles in Asia increased extracranial atherosclerotic disease prevalence. ${ }^{179}$ Secondly, ICAD is unique in the multiplicity of mechanisms that provoke stroke: artery-to-artery embolism (Figure 2), branch disease (Figure 3), thrombosis, and hemodynamic impairment have been implicated in brain infarction from intracranial atherosclerotic stenosis in imaging studies. ${ }^{180}$ MES detection with $T C D$, suggesting artery-to-artery embolism, has been in reported in 22\% of symptomatic ICAD stroke patients; ${ }^{181}$ this percentage climbs to $50 \%$ for severe stenosis, ${ }^{182}$ suggesting that arterial embolism could be the major cause of stroke in ICAD. MRI studies in Asian populations reported that $60 \%$ of strokes in ICAD arise from embolism, 15\% from branch infarction, 14\% from in situ occlusion, and less than 1\% from hemodynamic impairment. ${ }^{3}$

In the Warfarin versus Aspirin for Symptomatic Intracranial Disease (WASID) trial, stenosis of $>70 \%$ doubled the risk of stroke recurrence compared to symptomatic stenosis of $<70 \%$; in fact, the risk increased linearly with stenosis severity, peaking at a 30\% annual risk of recurrence for symptomatic stenosis of $80 \%$ to $89 \%$ and then declining for $>90 \%$ stenosis. ${ }^{183}$ The Chinese Intracranial Atherosclerosis (CICAS) study confirmed that the degree of stenosis correlates with recurrence
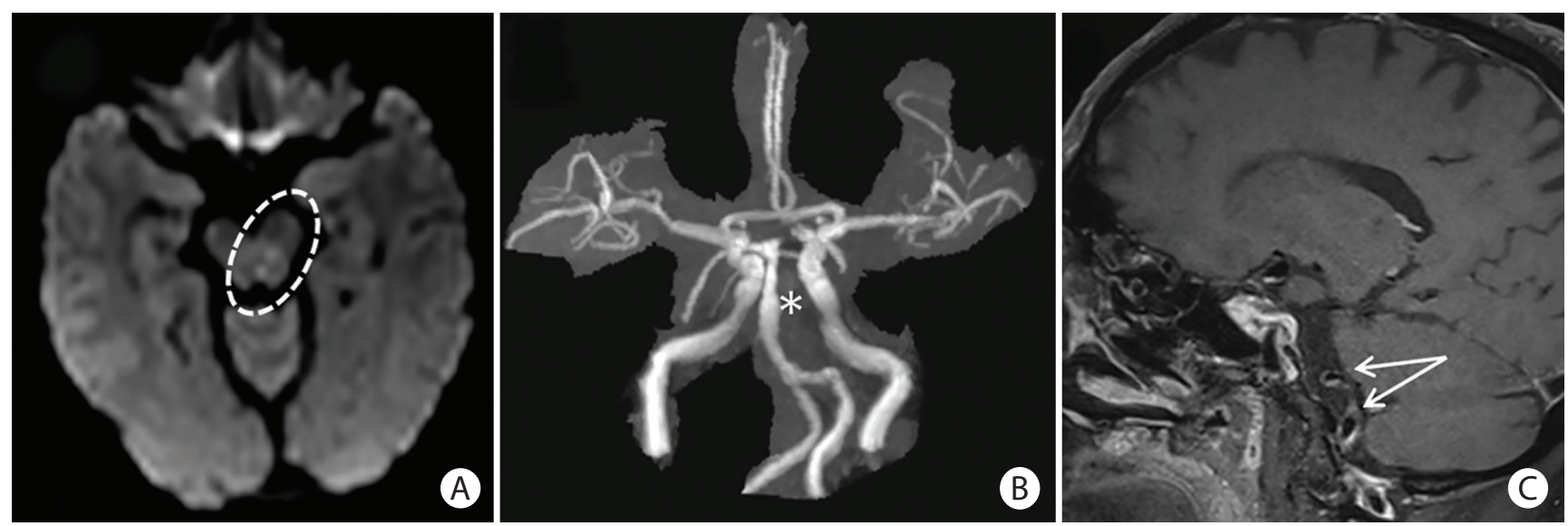

Figure 2. Symptomatic intracranial non-stenotic atherosclerotic plaque. A 67-year-old male with hypertension and diabetes mellitus, presented with acute-onset diplopia. On neurological examination Parinaud syndrome and incomplete left internuclear opthalmoplegia was identified. (A) Diffusion-weighted imaging showed two acute left mesencephalic ischemic lesions (oval). (B) Time-of-flight showed a focal stenosis of the distal basilar artery (asterisk). (C) 3-Tesla highresolution vessel wall-imaging disclosed a diffuse uptake of gadolinium by the atherosclerotic plaque in the wall of the basilar artery indicative of active inflammation (arrows). Artery-to-artery embolism to distal paramedian midbrain branches of an unstable non-atherosclerotic plaque in distal basilar artery was considered the underlying mechanism of acute cerebral ischemia. The patient was treated with dual antiplatelet therapy (clopidogrel load of $300 \mathrm{mg}$ followed by clopidogrel $75 \mathrm{mg}$ once a day and aspirin) for 3 months and colchicine ( $0.5 \mathrm{mg}$ once a day; off-label use for inflammatory atherosclerosis). Dual antiplatetet therapy was later substituted with single antiplatelet therapy (clopidogrel $75 \mathrm{mg}$ ). The patient experienced no recurrence during the 6-month follow-up period. 

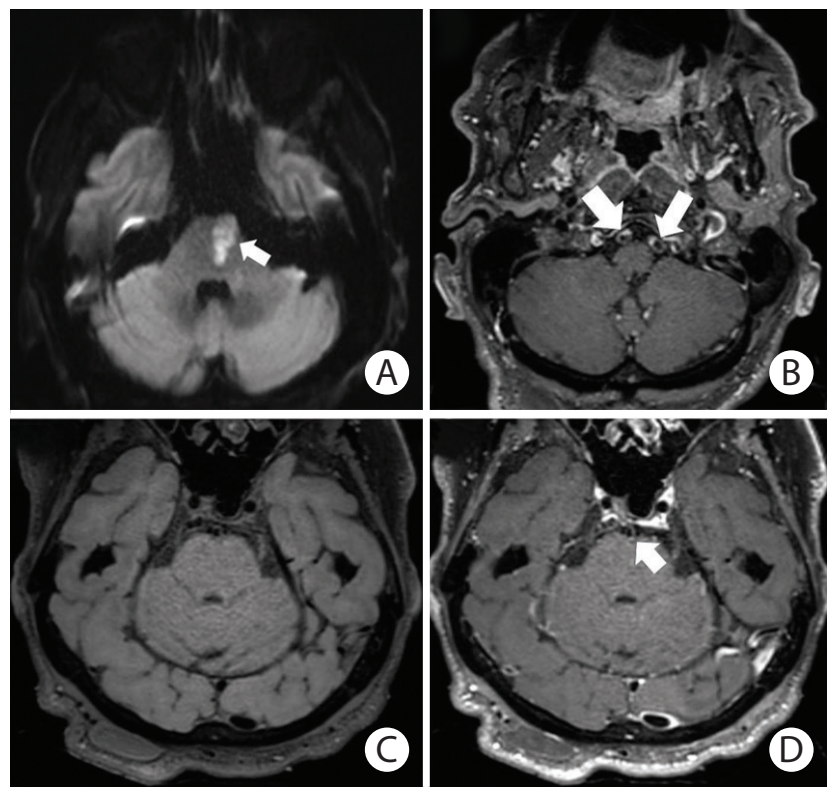

Figure 3. Branch-occlusive disease of the pons. (A) Diffusion-weighted image showing a left medial pontine infarction (arrow) along the left paramedian pontine artery territory (penetrating branch of basilar artery). (B) Post-contrast T1-weighted SPACE (Sampling Perfection with Application optimized Contrast using different angle Evolutions) image showing mural enhancement of both vertebral arteries (arrows). Patchy, eccentric pattern of contrast enhancement is consistent with atheromatous lesions. (C) Preand (D) post-contrast T1-weighted SPACE images showing uneven mural enhancement of the basilar artery ( $D$, arrow) indicating atheromatosis at the level of the pons.

risk; however, the correlation was moderate and other factors, such as a complete circle of Willis, seemed to play a more important role. ${ }^{184}$

Atherosclerotic plaques resulting in stenosis of $<50 \%$ can also lead to stroke. Branch atheromatous disease results in occlusion of the orifices of penetrating branches of the middle cerebral or basilar artery; it is commonly misdiagnosed as small vessel disease (lacunar stroke). ${ }^{185} \mathrm{MRI}$ with HR vessel wall imaging has been used to reveal this elusive cause of stroke, which is usually related to non-stenotic atherosclerotic plaques that cannot be detected with conventional lumenography-based imaging modalities (Figure 3). ${ }^{186}$ Up to 36\% of deep infarcts of the lenticulostriate arteries and 60\% of infarcts involving the anterior pontine arteries group in Asians have been attributed to ICAD. ${ }^{187} \mathrm{Ad}-$ vanced imaging with stronger magnetic fields may identify even more intracranial atheromatosis. ${ }^{188}$

HR MRI is an increasingly valuable tool because it can provide data on intracranial plaque vulnerability. ${ }^{189} \mathrm{IPH}$ has been described in symptomatic plaques in postmortem studies ${ }^{190}$ and has been frequently found as high signal in T1 MRI in symptomatic plaques. ${ }^{191}$ Lipid component, plaque morphology, and neovasculature are plaque characteristics that seem to indicate increased stroke risk; further development of imaging methods may help to identify high-risk individuals who may benefit from aggressive treatment. ${ }^{192}$ As with any site of atherosclerotic disease, stroke risk is much lower for asymptomatic ICAD in stroke patients whose workup revealed intracranial stenosis irrelevant to the index event. ${ }^{193}$ There are limited data on the risk of ICAD in healthy individuals; however, it seems that asymptomatic ICAD is an independent risk factor for stroke but carries a low risk of becoming symptomatic, suggesting that aggressive global reduction of $\mathrm{CV}$ risk may be more appropriate than local interventions targeted to the asymptomatic plaque. ${ }^{194}$ In the WASID trial, there was no difference in stroke recurrence between the anterior and the posterior circulation; however, in the CICAS study, posterior circulation ICAD stroke carried an increased risk of recurrence. A recent autopsy study showed that atherosclerosis is less frequent in the posterior circulation arteries and presents preferentially outward remodeling (resulting less frequently in focal stenosis) compared to anterior circulation arteries. ${ }^{195} \mathrm{An}$ overview of risk factors for stroke associated with ICAD is shown in Table 2. ${ }^{49,162,181-184,190-194,196-208}$

Regardless of stroke mechanisms, plaque location, or characteristics, ICAD is the expression of a single disease: atherosclerosis. There is clear evidence that the best secondary prevention strategy for ICAD stroke is aggressive BMT. An LDL of $<70 \mathrm{mg} /$ $\mathrm{dL}$, SBP of $<140 \mathrm{~mm} \mathrm{Hg}$ (or $<130 \mathrm{~mm} \mathrm{Hg}$ in diabetic patients), and a comprehensive lifestyle modification program resulted in $12 \%$ yearly risk of stroke or death for symptomatic ICAD of $>70 \%$ in the Stenting and Aggressive Medical Management for the Prevention of Recurrent Stroke in Intracranial Stenosis (SAMMPRIS) trial. ${ }^{192}$ Medical treatment consisting of DAPT, one drug from each major class of antihypertensive agents, and high-intensity statin therapy led to much lower recurrence rates compared with the preceding WASID, ${ }^{183}$ in which patients in the single antiplatelet (aspirin) arm received standard risk factor management and the 1-year rate of stroke or death from vascular causes was $25 \%$. Short-term ( $<90$-day) DAPT for acute ICAD stroke is considered reasonable in current guidelines (class Ilb; evidence level B). DAPT in ICAD stroke patients resulted in significant MES reduction as recorded on TCD within days of treatment. ${ }^{209}$ However, the low recurrence rates for patients on DAPT have not been replicated in a prospective registry ${ }^{210}$ or in a post hoc analysis of a RCT with ICAD patients. ${ }^{211}$

Percutaneous transluminal angioplasty and stenting (PTAS) for symptomatic ICAD is associated with adverse periprocedural and long-term cerebrovascular events, both ischemic and hemorrhagic. PTAS was associated with a higher risk of recurrent ischemic stroke in the territory of qualifying vessel both 
Table 2. Risk factors of intracranial atherosclerotic disease and associated features

\begin{tabular}{|c|c|}
\hline Risk factors & References \\
\hline Older age & $194,196,197$ \\
\hline Non-caucasian race & 198,199 \\
\hline Female sex & 197 \\
\hline Symptomatic plaque & 193 \\
\hline Stenosis > 70\% & 183 \\
\hline Stenosis progression & 200 \\
\hline Microembolic signals on transcranial Doppler & 181,182 \\
\hline Intraplaque hemorrhage & 190,191 \\
\hline Lipid content, neovasculature, thrombus & 192 \\
\hline Hemodynamic characteristics of stenosis & 201 \\
\hline Posterior circulation & 184,202 \\
\hline Extracranial carotid stenosis & 202 \\
\hline Coronary artery disease & 202 \\
\hline Absence of collaterals & 203,204 \\
\hline Older infarct in the ICAD territory & 197,205 \\
\hline$\geq 2$ Affected arteries (vs. 1) & 206 \\
\hline Multiple or subcorticocortical acute infarcts & 207 \\
\hline Stroke as index event (vs. TIA) & 197 \\
\hline Diabetes mellitus & 197 \\
\hline Dyslipidemia & 49,194 \\
\hline Hypertension & $49,162,194$ \\
\hline Metabolic syndrome & 208 \\
\hline
\end{tabular}

Demographic patient characteristics, plaque features as shown in imaging, location of stenosis, presence of collaterals, extent of atherosclerotic disease, and atherosclerotic risk factors may predict stroke due to ICAD.

ICAD, intracranial atherosclerotic disease; TIA, transient ischemic attack.

within 30 days and 1 year, a higher risk of any ischemic stroke within 30 days from stroke, and a higher risk for intracranial hemorrhage both within 30 days and 1 year; furthermore, the composite outcome of any stroke or death within 1 year and 2 years was higher in PTAS than in medical therapy. ${ }^{212}$ Perforator occlusion is likely causal for three out of four periprocedural ischemic strokes, presumably due to plaque debris being displaced or "snowplowed" over the perforator vessels during angioplasty or stent deployment. ${ }^{213}$ Apart from the procedure-related ischemic stroke, the risk of cerebral ischemia in the territory of the stenotic artery remained increased 30 days post-intervention. Finally, an unexpectedly high risk of intracranial hemorrhage after stenting was consistently documented in RCTs, especially in severe stenosis with small vessel diameter; this was related to vessel perforation (resulting in subarachnoid hemorrhage) and reperfusion injury, periprocedural anticoagulation, and clopidogrel load in patients with severe hemodynamic impairment. An ongoing multicenter RCT in China will include ICAD TIA and stroke patients not earlier than 3 weeks and no later than 12 months after the index event caused by
$>70 \%$ stenosis of a major intracranial artery with a $2-$ to 4-mm diameter confirmed by digital subtraction angiography. ${ }^{214}$ Patients will be randomized to either BMT or BMT plus stenting with a self-expanding Wingspan device. Until the publication of positive outcomes in RCTs, PTAS is not indicated for symptomatic ICAD stenosis unless there is recurrence despite BMT.

\section{Conclusions}

The main current updates in the prevention of atherosclerotic stroke include the potential of anti-inflammatory agents to offer additional risk reduction on top of BMT consisting of BP, blood glucose, and blood cholesterol control as well as optimal antiplatelet therapies and lifestyle modifications. Aggressive $L D L$ reduction with high-dose statins coupled with ezetimibe and/or PSCK9 inhibitors further reduce the risk of cardiovascular events in patients with stroke or MI. The combination of low-dose anticoagulation ( $2.5 \mathrm{mg}$ of rivaroxaban twice daily) and antiplatelet (100 mg of aspirin) therapies appears to be 
superior to single antiplatelet or anticoagulation therapy for the secondary prevention of patients with stable carotid artery disease. Carotid and coronary revascularization procedures appear to offer little or no supplementary benefit for patients with stable (or asymptomatic) coronary or carotid artery disease compared to BMT. High-resolution vessel-wall imaging MRI may provide a reliable, non-invasive neuroimaging marker of unstable atherosclerotic plaque in extracranial and intracranial vessels.

\section{Disclosure}

The authors have no financial conflicts of interest.

\section{Acknowledgments}

Dong-Eog Kim was supported by Global Research Lab (GRL) program (NRF-2015K1A1A2028228) of the National Research Foundation, funded by the Korean government, Republic of Korea.

\section{References}

1. McGill HC Jr, McMahan CA, Zieske AW, Sloop GD, Walcott

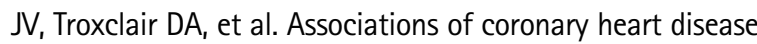
risk factors with the intermediate lesion of atherosclerosis in youth. The Pathobiological Determinants of Atherosclerosis in Youth (PDAY) Research Group. Arterioscler Thromb Vasc Biol 2000;20:1998-2004.

2. Randomised trial of cholesterol lowering in 4444 patients with coronary heart disease: the Scandinavian Simvastatin Survival Study (4S). Lancet 1994:344:1383-1389.

3. Kim JS, Nah HW, Park SM, Kim SK, Cho KH, Lee J, et al. Risk factors and stroke mechanisms in atherosclerotic stroke: intracranial compared with extracranial and anterior compared with posterior circulation disease. Stroke 2012;43:33133318.

4. O'Donnell MJ, Chin SL, Rangarajan S, Xavier D, Liu L, Zhang H, et al. Global and regional effects of potentially modifiable risk factors associated with acute stroke in 32 countries (INTERSTROKE): a case-control study. Lancet 2016;388:761-775.

5. Kawachi I, Colditz GA, Stampfer MJ, Willett WC, Manson JE, Rosner $B$, et al. Smoking cessation and decreased risk of stroke in women. JAMA 1993;269:232-236.

6. U.S. Department of Health and Human Services. 2008 Physical activity guidelines for Americans. http://www.health.gov/ paguidelines. Accessed May 23, 2018.

7. Strazzullo P, D'Elia L, Cairella G, Garbagnati F, Cappuccio FP, Scalfi L. Excess body weight and incidence of stroke: meta- analysis of prospective studies with 2 million participants. Stroke 2010;41:e418-e426.

8. Prospective Studies Collaboration, Whitlock G, Lewington $\mathrm{S}$, Sherliker $\mathrm{P}$, Clarke R, Emberson J, et al. Body-mass index and cause-specific mortality in 900000 adults: collaborative analyses of 57 prospective studies. Lancet 2009;373:10831096.

9. Eckel RH, Jakicic JM, Ard JD, de Jesus JM, Houston Miller $N$, Hubbard VS, et al. 2013 AHA/ACC guideline on lifestyle management to reduce cardiovascular risk: a report of the American College of Cardiology/American Heart Association Task Force on Practice Guidelines. Circulation 2014;129(25 Suppl 2):S76-S99.

10. Estruch $R$, Ros $E$, Salas-Salvadó J, Covas Ml, Corella D, Arós $F_{1}$ et al. Primary prevention of cardiovascular disease with a Mediterranean diet. N Eng/ J Med 2013;368:1279-1290.

11. Sarkkinen ES, Kastarinen MJ, Niskanen $T H$, Karjalainen PH, Venäläinen TM, Udani JK, et al. Feasibility and antihypertensive effect of replacing regular salt with mineral salt-rich in magnesium and potassium-in subjects with mildly elevated blood pressure. Nutr J 2011;10:88.

12. Kelli HM, Hammadah M, Ahmed H, Ko YA, Topel M, Samman-Tahhan $A$, et al. Association between living in food deserts and cardiovascular risk. Circ Cardiovasc Qual Outcomes 2017;10:e003532.

13. Pennlert J, Asplund K, Glader EL, Norrving B, Eriksson M. Socioeconomic status and the risk of stroke recurrence: persisting gaps observed in a nationwide Swedish study 2001 to 2012. Stroke 2017:48:1518-1523.

14. Baigent C, Keech A, Kearney PM, Blackwell L, Buck G, Pollicino

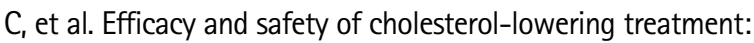
prospective meta-analysis of data from 90,056 participants in 14 randomised trials of statins. Lancet 2005;366:1267-1278.

15. Sturgeon JD, Folsom AR, Longstreth WT Jr, Shahar E, Rosamond WD, Cushman M. Risk factors for intracerebral hemorrhage in a pooled prospective study. Stroke 2007;38:27182725.

16. Prospective Studies Collaboration, Lewington $\mathrm{S}$, Whitlock $\mathrm{G}$, Clarke R, Sherliker P, Emberson J, et al. Blood cholesterol and vascular mortality by age, sex, and blood pressure: a metaanalysis of individual data from 61 prospective studies with 55,000 vascular deaths. Lancet 2007;370:1829-1839.

17. Iso $H_{1}$ Jacobs DR Jr, Wentworth D, Neaton JD, Cohen JD. Serum cholesterol levels and six-year mortality from stroke in 350,977 men screened for the multiple risk factor intervention trial. N Engl J Med 1989;320:904-910.

18. Chan DK, O'Rourke F, Shen $\mathrm{Q}$, Mak JC, Hung WT. Meta-analysis of the cardiovascular benefits of intensive lipid lowering 
with statins. Acta Neurol Scand 2011;124:188-195.

19. Cannon CP, Steinberg BA, Murphy SA, Mega JL, Braunwald E. Meta-analysis of cardiovascular outcomes trials comparing intensive versus moderate statin therapy. J Am Coll Cardiol 2006;48:438-445.

20. Everett BM, Glynn RJ, MacFadyen JG, Ridker PM. Rosuvastatin in the prevention of stroke among men and women with elevated levels of C-reactive protein: Justification for the Use of Statins in Prevention: an Intervention Trial Evaluating Rosuvastatin (JUPITER). Circulation 2010;121:143-150.

21. Hackam DG, Woodward M, Newby LK, Bhatt DL, Shao M, Smith $E_{\text {, }}$ et al. Statins and intracerebral hemorrhage: collaborative systematic review and meta-analysis. Circulation $2011 ; 124: 2233-2242$.

22. D'Agostino RB Sr, Vasan RS, Pencina MJ, Wolf PA, Cobain M, Massaro JM, et al. General cardiovascular risk profile for use in primary care: the Framingham Heart Study. Circulation 2008;117:743-753.

23. Conroy RM, Pyörälä $K$, Fitzgerald AP, Sans $S$, Menotti $A$, De Backer $G$, et al. Estimation of ten-year risk of fatal cardiovascular disease in Europe: the SCORE project. Eur Heart $J$ 2003;24:987-1003.

24. Goff DC Jr, Lloyd-Jones DM, Bennett G, Coady S, D'Agostino RB, Gibbons R, et al. 2013 ACC/AHA guideline on the assessment of cardiovascular risk: a report of the American College of Cardiology/American Heart Association Task Force on Practice Guidelines. Circulation 2014;129(25 Suppl 2):S49S73.

25. Lackland DT, Elkind MS, D'Agostino R Sr, Dhamoon MS, Goff DC Jr, Higashida RT, et al. Inclusion of stroke in cardiovascular risk prediction instruments: a statement for healthcare professionals from the American Heart Association/American Stroke Association. Stroke 2012;43:1998-2027.

26. Stone NJ, Robinson JG, Lichtenstein AH, Bairey Merz CN, Blum $C B$, Eckel RH, et al. 2013 ACC/AHA guideline on the treatment of blood cholesterol to reduce atherosclerotic cardiovascular risk in adults: a report of the American College of Cardiologyl American Heart Association Task Force on Practice Guidelines. J Am Coll Cardiol 2014;63(25 Pt B):2889-2934.

27. Cannon CP, Blazing MA, Giugliano RP, McCagg A, White JA, Theroux $P$, et al. Ezetimibe added to statin therapy after acute coronary syndromes. N Engl J Med 2015;372:23872397.

28. Sabatine MS, Giugliano RP, Keech AC, Honarpour N, Wiviott SD, Murphy SA, et al. Evolocumab and clinical outcomes in patients with cardiovascular disease. N Engl J Med 2017;376: 1713-1722.

29. Jellinger PS, Handelsman $Y$, Rosenblit PD, Bloomgarden $Z T$,
Fonseca VA, Garber AJ, et al. American Association of Clinical Endocrinologists and American College of Endocrinology guidelines for management of dyslipidemia and prevention of cardiovascular disease. Endocr Pract 2017;23(Suppl 2):187.

30. Writing Committee, Lloyd-Jones DM, Morris PB, Ballantyne CM, Birtcher KK, Daly DD Jr, et al. 2016 ACC expert consensus decision pathway on the role of non-statin therapies for LDL-cholesterol lowering in the management of atherosclerotic cardiovascular disease risk: a report of the American College of Cardiology Task Force on Clinical Expert Consensus Documents. J Am Coll Cardiol 2016;68:92-125.

31. Catapano AL, Graham I, De Backer G, Wiklund O, Chapman MJ, Drexel H, et al. 2016 ESC/EAS guidelines for the management of dyslipidaemias. Eur Heart J 2016;37:2999-3058.

32. BaerJ. AACE and EAS lipid guidelines. http://www.acc.org/ latest-in-cardiology/articles/2017/08/11/08/35/aace-andeas-lipid-guidelines. 2017. Accessed May 23, 2018.

33. Landmesser U, Chapman MJ, Stock JK, Amarenco P, Belch JJF, Borén J, et al. 2017 Update of ESC/EAS Task Force on practical clinical guidance for proprotein convertase subtilisin/kexin type 9 inhibition in patients with atherosclerotic cardiovascular disease or in familial hypercholesterolaemia. Eur Heart J 2018;39:1131-1143.

34. Catapano A, Toth PP, Tomassini JE, Tershakovec AM. The efficacy and safety of ezetimibe coadministered with statin therapy in various patient groups. Clin Lipidol 2013;8:13-41.

35. Pagidipati NJ, Navar AM, Mulder H, Sniderman AD, Peterson ED, Pencina MJ. Comparison of recommended eligibility for primary prevention statin therapy based on the US Preventive Services Task Force recommendations vs the ACC/AHA guidelines. JAMA 2017;317:1563-1567.

36. Kazi DS, Moran AE, Coxson PG, Penko J, Ollendorf DA, Pearson SD, et al. Cost-effectiveness of PCSK9 inhibitor therapy in patients with heterozygous familial hypercholesterolemia or atherosclerotic cardiovascular disease. JAMA 2016;316:743-753.

37. Amarenco P, Bogousslavsky J, Callahan A 3rd, Goldstein LB,

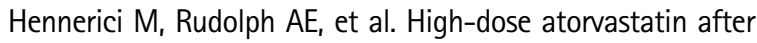
stroke or transient ischemic attack. N Engl J Med 2006;355: 549-559.

38. Dhamoon MS, Tai W, Boden-Albala B, Rundek T, Paik MC, Sacco $R L$, et al. Risk of myocardial infarction or vascular death after first ischemic stroke: the Northern Manhattan Study. Stroke 2007;38:1752-1758.

39. Bassand JP, Accetta G, Al Mahmeed W, Corbalan R, Eikelboom J, Fitzmaurice DA, et al. Risk factors for death, stroke, and bleeding in 28,628 patients from the GARFIELD-AF registry: rationale for comprehensive management of atrial fi- 
brillation. PLoS One 2018;13:e0191592.

40. Flint $A C$, Kamel $H$, Navi BB, Rao VA, Faigeles BS, Conell $C$, et al. Inpatient statin use predicts improved ischemic stroke discharge disposition. Neurology 2012;78:1678-1683.

41. Tsivgoulis G, Katsanos AH, Sharma VK, Krogias C, Mikulik R, Vadikolias $K$, et al. Statin pretreatment is associated with better outcomes in large artery atherosclerotic stroke. Neurology 2016;86:1103-1111.

42. Safouris A, Krogias C, Sharma VK, Katsanos AH, Faissner $S$, Roussopoulou $A$, et al. Statin pretreatment and microembolic signals in large artery atherosclerosis. Arterioscler Thromb Vasc Biol 2017;37:1415-1422.

43. Tsivgoulis G, Vadikolias K, Heliopoulos I, Katsibari C, Voumvourakis $\mathrm{K}$, Tsakaldimi S, et al. Prevalence of symptomatic intracranial atherosclerosis in Caucasians: a prospective, multicenter, transcranial Doppler study. J Neuroimaging 2014;24:11-17.

44. Lewington S, Clarke R, Qizilbash N, Peto R, Collins R; Prospective Studies Collaboration. Age-specific relevance of usual blood pressure to vascular mortality: a meta-analysis of individual data for one million adults in 61 prospective studies. Lancet 2002;360:1903-1913.

45. Xie $X$, Atkins $E$, Lv J, Bennett $A$, Neal B, Ninomiya T, et al. Effects of intensive blood pressure lowering on cardiovascular and renal outcomes: updated systematic review and metaanalysis. Lancet 2016;387:435-443.

46. Katsanos AH, Filippatou A, Manios E, Deftereos S, Parissis J, Frogoudaki $A$, et al. Blood pressure reduction and secondary stroke prevention: a systematic review and metaregression analysis of randomized clinical trials. Hypertension 2017;69: 171-179.

47. Whelton PK, Carey RM, Aronow WS, Casey DE Jr, Collins KJ, Dennison Himmelfarb C, et al. 2017 ACC/AHA/AAPA/ABC/ ACPM/AGS/APhA/ASH/ASPC/NMA/PCNA guideline for the prevention, detection, evaluation, and management of high blood pressure in adults: executive summary: a report of the American College of Cardiology/American Heart Association Task Force on clinical practice guidelines. Hypertension 2018;71:1269-1324.

48. SPS3 Study Group, Benavente OR, Coffey CS, Conwit R, Hart $R G$, McClure LA, et al. Blood-pressure targets in patients with recent lacunar stroke: the SPS3 randomised trial. Lancet 2013;382:507-515.

49. Chaturvedi S, Turan TN, Lynn MJ, Kasner SE, Romano J, Cotsonis $\mathrm{G}$, et al. Risk factor status and vascular events in patients with symptomatic intracranial stenosis. Neurology 2007;69:2063-2068.

50. Park JH, Ovbiagele B. Post-stroke diastolic blood pressure and risk of recurrent vascular events. Eur J Neurol 2017;24:14161423.
51. Ovbiagele B, Diener HC, Yusuf S, Martin RH, Cotton D, Vinisko $\mathrm{R}$, et al. Level of systolic blood pressure within the normal range and risk of recurrent stroke. JAMA 2011;306:21372144.

52. Ohira T, Shahar E, Chambless LE, Rosamond WD, Mosley TH Jr, Folsom AR. Risk factors for ischemic stroke subtypes: the Atherosclerosis Risk in Communities study. Stroke 2006;37:24932498.

53. Janghorbani M, Hu FB, Willett WC, Li TY, Manson JE, Logroscino G, et al. Prospective study of type 1 and type 2 diabetes and risk of stroke subtypes: the Nurses' Health Study. Diabetes Care 2007;30:1730-1735.

54. Woo CH, Shishido T, McClain C, Lim JH, Li JD, Yang J, et al. Extracellular signal-regulated kinase 5 SUMOylation antagonizes shear stress-induced antiinflammatory response and endothelial nitric oxide synthase expression in endothelial cells. Circ Res 2008;102:538-545.

55. Banerjee C, Moon YP, Paik MC, Rundek T, Mora-McLaughlin C, Vieira JR, et al. Duration of diabetes and risk of ischemic stroke: the Northern Manhattan Study. Stroke 2012;43:12121217.

56. Garber AJ, Abrahamson MJ, Barzilay Jl, Blonde L, Bloomgarden ZT, Bush MA, et al. Consensus statement by the American Association of Clinical Endocrinologists and American College of Endocrinology on the comprehensive type 2 diabetes management algorithm: 2018 executive summary. Endocr Pract 2018;24:91-120.

57. ACCORD Study Group, Cushman WC, Evans GW, Byington RP, Goff DC Jr, Grimm RH Jr, et al. Effects of intensive bloodpressure control in type 2 diabetes mellitus. N Engl J Med 2010;362:1575-1585.

58. Butalia S, Leung AA, Ghali WA, Rabi DM. Aspirin effect on the incidence of major adverse cardiovascular events in patients with diabetes mellitus: a systematic review and metaanalysis. Cardiovasc Diabetol 2011;10:25.

59. Kobzar G, Mardla V, Samel N. Short-term exposure of platelets to glucose impairs inhibition of platelet aggregation by cyclooxygenase inhibitors. Platelets $2011 ; 22: 338-344$.

60. American Diabetes Association. 9. Cardiovascular disease and risk management: standards of medical care in diabetes-2018. Diabetes Care 2018;41(Suppl 1):S86-S104.

61. Zinman B, Wanner C, Lachin JM, Fitchett D, Bluhmki E, Hantel $\mathrm{S}$, et al. Empagliflozin, cardiovascular outcomes, and mortality in type 2 diabetes. N Engl J Med 2015;373:21172128.

62. Neal B, Perkovic V, Mahaffey KW, de Zeeuw D, Fulcher G, Erondu $N$, et al. Canagliflozin and cardiovascular and renal events in type 2 diabetes. N Engl J Med 2017;377:644-657. 
63. Marso SP, Daniels GH, Brown-Frandsen K, Kristensen P, Mann $J F$, Nauck MA, et al. Liraglutide and cardiovascular outcomes in type 2 diabetes. N Engl J Med 2016;375:311-322.

64. Dormandy JA, Charbonnel B, Eckland DJ, Erdmann E, MassiBenedetti M, Moules IK, et al. Secondary prevention of macrovascular events in patients with type 2 diabetes in the PROactive Study (PROspective pioglitAzone Clinical Trial In macroVascular Events): a randomized controlled trial. Lancet 2005;366:1279-1289.

65. Mazzone T, Meyer PM, Feinstein SB, Davidson MH, Kondos GT, D'Agostino RB Sr, et al. Effect of pioglitazone compared with glimepiride on carotid intima-media thickness in type 2 diabetes: a randomized trial. JAMA 2006;296:2572-2581.

66. International Stroke Trial Collaborative Group. The International Stroke Trial (IST): a randomised trial of aspirin, subcutaneous heparin, both, or neither among 19435 patients with acute ischaemic stroke. Lancet 1997;349:1569-1581.

67. ESPRIT Study Group, Halkes PH, van Gijn J, Kappelle $\sqcup$, Koudstaal PJ, Algra A. Aspirin plus dipyridamole versus aspirin alone after cerebral ischaemia of arterial origin (ESPRIT): randomised controlled trial. Lancet 2006;367:1665-1673.

68. Diener HC, Sacco RL, Yusuf S, Cotton D, Ounpuu S, Lawton WA, et al. Effects of aspirin plus extended-release dipyridamole versus clopidogrel and telmisartan on disability and cognitive function after recurrent stroke in patients with ischaemic stroke in the Prevention Regimen for Effectively Avoiding Second Strokes (PRoFESS) trial: a double-blind, active and placebo-controlled study. Lancet Neurol 2008;7:875884.

69. CAPRIE Steering Committee. A randomised, blinded, trial of clopidogrel versus aspirin in patients at risk of ischaemic events (CAPRIE). Lancet 1996;348:1329-1339.

70. Ringleb PA, Bhatt DL, Hirsch AT, Topol EJ, Hacke W; Clopidogrel Versus Aspirin in Patients at Risk of Ischemic Events Investigators. Benefit of clopidogrel over aspirin is amplified in patients with a history of ischemic events. Stroke 2004;35:528-532.

71. Lee $M, W u Y L$, Saver JL, Lee HC, Lee JD, Chang KC, et al. Is clopidogrel better than aspirin following breakthrough strokes while on aspirin? A retrospective cohort study. BMJ Open 2014;4:e006672.

72. Diener HC, Bogousslavsky J, Brass LM, Cimminiello C, Csiba L, Kaste $M$, et al. Aspirin and clopidogrel compared with clopidogrel alone after recent ischaemic stroke or transient ischaemic attack in high-risk patients (MATCH): randomised, double-blind, placebo-controlled trial. Lancet 2004;364:331337.

73. Bhatt DL, Fox KA, Hacke W, Berger PB, Black HR, Boden WE, et al. Clopidogrel and aspirin versus aspirin alone for the preven- tion of atherothrombotic events. N Engl J Med 2006;354: 1706-1717.

74. Benavente $O R$, White $C L$, Pearce $L$, Pergola $P$, Roldan $A$, Benavente $M F$, et al. The secondary prevention of small subcortical strokes (SPS3) study. Int J Stroke 2011;6:164-175.

75. Wang Y, Wang Y, Zhao X, Liu L, Wang D, Wang C, et al. Clopidogrel with aspirin in acute minor stroke or transient ischemic attack. N Engl J Med 2013;369:11-19.

76. Johnston SC, Easton JD, Farrant M, Barsan W, Conwit RA, Elm JJ, et al. Clopidogrel and aspirin in acute ischemic stroke and high-risk TIA. N Engl J Med 2018 May 16 [Epub]. https:// doi.org/10.1056/NEJMoa1800410.

77. Amarenco P, Albers GW, Denison H, Easton JD, Evans SR, Held $P$, et al. Efficacy and safety of ticagrelor versus aspirin in acute stroke or transient ischaemic attack of atherosclerotic origin: a subgroup analysis of SOCRATES, a randomised, double-blind, controlled trial. Lancet Neurol 2017;16:301310.

78. Kwon SU, Cho YJ, Koo JS, Bae HJ, Lee YS, Hong KS, et al. Cilostazol prevents the progression of the symptomatic intracranial arterial stenosis: the multicenter double-blind placebo-controlled trial of cilostazol in symptomatic intracranial arterial stenosis. Stroke 2005;36:782-786.

79. Kwon SU, Hong KS, Kang DW, Park JM, Lee JH, Cho YJ, et al. Efficacy and safety of combination antiplatelet therapies in patients with symptomatic intracranial atherosclerotic stenosis. Stroke 2011;42:2883-2890.

80. Kim DE, Kim JY, Jeong SW, Cho YJ, Park JM, Lee JH, et al. Association between changes in lipid profiles and progression of symptomatic intracranial atherosclerotic stenosis: a prospective multicenter study. Stroke 2012;43:1824-1830.

81. Kim BJ, Lee EJ, Kwon SU, Park JH, Kim YJ, Hong KS, et al. Prevention of cardiovascular events in Asian patients with ischaemic stroke at high risk of cerebral haemorrhage (PICASSO): a multicentre, randomised controlled trial. Lancet Neurol 2018;17:509-518.

82. Eikelboom JW, Connolly SJ, Bosch J, Dagenais GR, Hart RG, Shestakovska 0, et al. Rivaroxaban with or without aspirin in stable cardiovascular disease. N Engl J Med 2017;377:13191330.

83. Mega JL, Braunwald E, Wiviott SD, Bassand JP, Bhatt DL, Bode $C$, et al. Rivaroxaban in patients with a recent acute coronary syndrome. N Engl J Med 2012;366:9-19.

84. Katsanos $A H$, Mavridis D, Parissis J, Deftereos $S$, Frogoudaki $A$, Vrettou $A R$, et al. Novel oral anticoagulants for the secondary prevention of cerebral ischemia: a network metaanalysis. Ther Adv Neurol Disord 2016;9:359-368.

85. Anand SS, Bosch J, Eikelboom JW, Connolly SJ, Diaz R, Wi- 


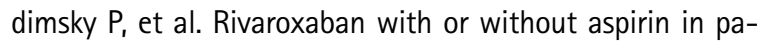
tients with stable peripheral or carotid artery disease: an international, randomised, double-blind, placebo-controlled trial. Lancet 2017 Nov 10 [Epub]. https://doi.org/10.1016/ S0140-6736(17)32409-1.

86. Marnane $M$, Merwick $A$, Sheehan OC, Hannon N, Foran $P_{\text {, }}$ Grant T, et al. Carotid plaque inflammation on 18F-fluorodeoxyglucose positron emission tomography predicts early stroke recurrence. Ann Neurol 2012;71:709-718.

87. Ridker PM, Everett BM, Thuren T, MacFadyen JG, Chang WH,

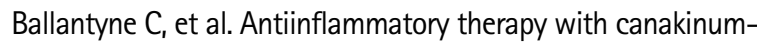
ab for atherosclerotic disease. N Engl J Med 2017;377:11191131.

88. Canakinumab (Ilaris): Common Drug Review. Ottawa, ON: Canadian Agency for Drugs and Technologies in Health, 2016. https://www.ncbi.nlm.nih.gov/books/NBK409908.

89. Nidorf SM, Eikelboom JW, Budgeon CA, Thompson PL. Lowdose colchicine for secondary prevention of cardiovascular disease. J Am Coll Cardiol 2013;61:404-410.

90. Tsivgoulis G, Katsanos AH, Giannopoulos G, Panagopoulou $V_{1}$ Jatuzis $D$, Lemmens $R$, et al. The role of colchicine in the prevention of cerebrovascular ischemia. Curr Pharm Des 2018;24: 668-674.

91. U.S. National Library of Medicine. Colchicine for prevention of vascular inflammation in non-cardioembolic stroke (CONVINCE). https://clinicaltrials.gov/ct2/show/NCT02898610. 2017. Assessed May 23, 2018.

92. Rothwell PM, Eliasziw M, Gutnikov SA, Fox AJ, Taylor DW, Mayberg MR, et al. Analysis of pooled data from the randomised controlled trials of endarterectomy for symptomatic carotid stenosis. Lancet 2003;361:107-116.

93. Howard VJ, Lutsep HL, Mackey A, Demaerschalk BM, Sam AD 2 nd, Gonzales NR, et al. Influence of sex on outcomes of stenting versus endarterectomy: a subgroup analysis of the Carotid Revascularization Endarterectomy versus Stenting Trial (CREST). Lancet Neurol 2011;10:530-537.

94. Rantner B, Kollerits B, Roubin GS, Ringleb PA, Jansen O, Howard G, et al. Early endarterectomy carries a lower procedural risk than early stenting in patients with symptomatic stenosis of the internal carotid artery: results from 4 randomized controlled trials. Stroke 2017;48:1580-1587.

95. Strömberg S, Gelin J, Osterberg T, Bergström GM, Karlström L, Osterberg $\mathrm{K}$, et al. Very urgent carotid endarterectomy confers increased procedural risk. Stroke 2012;43:1331-1335.

96. Tsivgoulis G, Kerasnoudis A, Krogias C, Vadikolias K, Meves $\mathrm{SH}$, Heliopoulos I, et al. Clopidogrel load for emboli reduction in patients with symptomatic carotid stenosis undergoing urgent carotid endarterectomy. Stroke 2012;43:1957-1960.
97. Jones DW, Goodney PP, Conrad MF, Nolan BW, Rzucidlo EM, Powell RJ, et al. Dual antiplatelet therapy reduces stroke but increases bleeding at the time of carotid endarterectomy. J Vasc Surg 2016;63:1262-1270.

98. Rothwell PM, Eliasziw M, Gutnikov SA, Warlow CP, Barnett HJ. Sex difference in the effect of time from symptoms to surgery on benefit from carotid endarterectomy for transient ischemic attack and nondisabling stroke. Stroke 2004;35:2855-2861.

99. Calvet D, Mas JL, Algra A, Becquemin JP, Bonati LH, Dobson $J$, et al. Carotid stenting: is there an operator effect? A pooled analysis from the carotid stenting trialists' collaboration. Stroke 2014;45:527-532.

100. Kernan WN, Ovbiagele B, Black HR, Bravata DM, Chimowitz MI, Ezekowitz MD, et al. Guidelines for the prevention of stroke in patients with stroke and transient ischemic attack: a guideline for healthcare professionals from the American Heart Association/American Stroke Association. Stroke 2014;45:2160-2236.

101. Hugl B, Oldenburg WA, Neuhauser B, Hakaim AG. Effect of age and gender on restenosis after carotid endarterectomy. Ann Vasc Surg 2006;20:602-608.

102. De Rango P, Brown MM, Leys D, Howard VJ, Moore WS, Paciaroni $M$, et al. Management of carotid stenosis in women: consensus document. Neurology 2013;80:2258-2268.

103. Molina CA, Selim MH. Carotid wars episode VI: return of the standard. Stroke 2013;44:2959-2960.

104. Barnett HJ, Taylor DW, Eliasziw M, Fox AJ, Ferguson GG, Haynes RB, et al. Benefit of carotid endarterectomy in patients with symptomatic moderate or severe stenosis. North American Symptomatic Carotid Endarterectomy Trial Collaborators. N Engl J Med 1998;339:1415-1425.

105. Rerkasem K, Rothwell PM. Systematic review of randomized controlled trials of patch angioplasty versus primary closure during carotid endarterectomy. Stroke 2010;41:e55-e56.

106. Brott TG, Hobson RW 2nd, Howard G, Roubin GS, Clark WM, Brooks $W$, et al. Stenting versus endarterectomy for treatment of carotid-artery stenosis. N Engl J Med 2010;363:1123.

107. Sharma VK, Paliwal PR, Ting EY, Chan BP, Teoh HL, Sinha AK. Abstract 147: plaque inflammation is associated with early cerebral ischemic events in symptomatic carotid stenosis. Stroke 2018;49:A147.

108. Kim DE, Kim JY, Schellingerhout D, Kim EJ, Kim HK, Lee S, et al. Protease imaging of human atheromata captures molecular information of atherosclerosis, complementing anatomic imaging. Arterioscler Thromb Vasc Biol 2010;30:449-456.

109. Economopoulos KP, Sergentanis TN, Tsivgoulis G, Mariolis AD, Stefanadis C. Carotid artery stenting versus carotid endarter- 
ectomy: a comprehensive meta-analysis of short-term and long-term outcomes. Stroke 2011;42:687-692.

110. Fine-Edelstein JS, Wolf PA, O'Leary DH, Poehlman H, Belanger $\mathrm{A}$, Kase CS, et al. Precursors of extracranial carotid atherosclerosis in the Framingham Study. Neurology 1994:44:10461050.

111. Meschia JF, Bushnell C, Boden-Albala B, Braun LT, Bravata DM, Chaturvedi $S$, et al. Guidelines for the primary prevention of stroke: a statement for healthcare professionals from the American Heart Association/American Stroke Association. Stroke 2014;45:3754-3832.

112. Abbott AL. Medical (nonsurgical) intervention alone is now best for prevention of stroke associated with asymptomatic severe carotid stenosis: results of a systematic review and analysis. Stroke 2009;40:e573-e583.

113. Executive Committee for the Asymptomatic Carotid Atherosclerosis Study. Endarterectomy for asymptomatic carotid artery stenosis. JAMA 1995;273:1421-1428.

114. Halliday A, Mansfield A, Marro J, Peto C, Peto R, Potter J, et al. Prevention of disabling and fatal strokes by successful carotid endarterectomy in patients without recent neurological symptoms: randomised controlled trial. Lancet 2004;363:14911502.

115. Halliday A, Harrison $M$, Hayter $E_{1}$ Kong $X$, Mansfield A, Marro $J$, et al. 10-Year stroke prevention after successful carotid endarterectomy for asymptomatic stenosis (ACST-1): a multicentre randomised trial. Lancet 2010;376:1074-1084.

116. Baker WH, Howard VJ, Howard G, Toole JF. Effect of contralateral occlusion on long-term efficacy of endarterectomy in the asymptomatic carotid atherosclerosis study (ACAS). ACAS Investigators. Stroke 2000;31:2330-2334.

117. Nicolaides AN, Kakkos SK, Griffin M, Sabetai M, Dhanjil S,

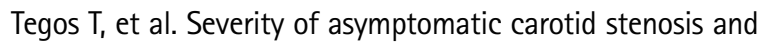
risk of ipsilateral hemispheric ischaemic events: results from the ACSRS study. Eur J Vasc Endovasc Surg 2005;30:275-284.

118. Al-Lamee R, Thompson D, Dehbi HM, Sen S, Tang K, Davies J, et al. Percutaneous coronary intervention in stable angina (ORBITA): a double-blind, randomised controlled trial. Lancet 2018;391:31-40.

119. Stergiopoulos K, Brown DL. Initial coronary stent implantation with medical therapy vs medical therapy alone for stable coronary artery disease: meta-analysis of randomized controlled trials. Arch Intern Med 2012;172:312-319.

120. Brown DL, Redberg RF. Last nail in the coffin for $\mathrm{PCl}$ in stable angina? Lancet 2018;391:3-4.

121. McPhee JT, Schanzer A, Messina LM, Eslami MH. Carotid artery stenting has increased rates of postprocedure stroke, death, and resource utilization than does carotid endarterec- tomy in the United States, 2005. J Vasc Surg 2008;48:14421450.

122. Naylor AR. Time to rethink management strategies in asymptomatic carotid artery disease. Nat Rev Cardiol 2011;9:116124.

123. Naylor AR. Why is the management of asymptomatic carotid disease so controversial? Surgeon 2015;13:34-43.

124. Rothwell PM, Warlow CP. Low risk of ischemic stroke in patients with reduced internal carotid artery lumen diameter distal to severe symptomatic carotid stenosis: cerebral protection due to low poststenotic flow? On behalf of the European Carotid Surgery Trialists' Collaborative Group. Stroke 2000;31:622-630.

125. Kargiotis O, Safouris A, Magoufis G, Georgala M, Roussopoulou $A$, Stamboulis $E$, et al. The role of neurosonology in the diagnosis and management of patients with carotid artery disease: a review. J Neuroimaging 2018;28:239-251.

126. Geroulakos G, Hobson RW, Nicolaides A. Ultrasonographic carotid plaque morphology in predicting stroke risk. Br J Surg 1996;83:582-587.

127. Brinjikji W, Rabinstein AA, Lanzino G, Murad MH, Williamson $\mathrm{EE}$, DeMarco JK, et al. Ultrasound characteristics of symptomatic carotid plaques: a systematic review and metaanalysis. Cerebrovasc Dis 2015;40:165-174.

128. Griffin M, Nicolaides $A$, Kyriacou E. Normalisation of ultrasonic images of atherosclerotic plaques and reproducibility of grey scale median using dedicated software. Int Angiol 2007;26:372-377.

129. Biasi GM, Froio A, Diethrich EB, Deleo G, Galimberti S, Mingazzini $P$, et al. Carotid plaque echolucency increases the risk of stroke in carotid stenting: the Imaging in Carotid Angioplasty and Risk of Stroke (ICAROS) study. Circulation 2004;110:756762.

130. Markus HS, King A, Shipley M, Topakian R, Cullinane M, Reihill $S$, et al. Asymptomatic embolisation for prediction of stroke in the Asymptomatic Carotid Emboli Study (ACES): a prospective observational study. Lancet Neurol 2010;9:663671.

131. Saba L, Caddeo G, Sanfilippo R, Montisci R, Mallarini G. CT and ultrasound in the study of ulcerated carotid plaque compared with surgical results: potentialities and advantages of multidetector row CT angiography. AJNR Am J Neuroradiol 2007;28:1061-1066.

132. Schroeder S, Kopp AF, Baumbach A, Meisner C, Kuettner A, Georg $C_{1}$ et al. Noninvasive detection and evaluation of atherosclerotic coronary plaques with multislice computed tomography. J Am Coll Cardiol 2001;37:1430-1435.

133. Singh N, Moody AR, Gladstone DJ, Leung G, Ravikumar R, 
Zhan J, et al. Moderate carotid artery stenosis: MR imagingdepicted intraplaque hemorrhage predicts risk of cerebrovascular ischemic events in asymptomatic men. Radiology 2009;252:502-508.

134. Meschia JF, Klaas JP, Brown RD Jr, Brott TG. Evaluation and management of atherosclerotic carotid stenosis. Mayo Clin Proc 2017;92:1144-1157.

135. Mott $M$, Koroshetz W, Wright CB. CREST-2: identifying the best method of stroke prevention for carotid artery stenosis: national institute of neurological disorders and stroke organizational update. Stroke 2017;48:e130-e131.

136. U.S. National Library of Medicine. Carotid endarterectomy versus carotid artery stenting in asymptomatic patients (ACST-2). https://clinicaltrials.gov/ct2/show/NCT00883402. 2017. Accessed May 23, 2018.

137. ECST-2. Protocol summary: version 3.10. 11 th November 2015. http://s489637516.websitehome.co.uk/ECST2/protocolsummary.htm. 2015. Accessed May 23, 2018.

138. Adams HP Jr, Bendixen BH, Kappelle $\sqcup$, Biller J, Love BB, Gordon $D L$, et al. Classification of subtype of acute ischemic stroke. Definitions for use in a multicenter clinical trial. TOAST. Trial of Org 10172 in Acute Stroke Treatment. Stroke 1993;24:35-41.

139. Naghavi M, Libby P, Falk E, Casscells SW, Litovsky S, Rumberger J, et al. From vulnerable plaque to vulnerable patient: a call for new definitions and risk assessment strategies: part I. Circulation 2003;108:1664-1672.

140. Falk E, Fuster V. Angina pectoris and disease progression. Circulation 1995;92:2033-2035.

141. Stary HC. Natural history and histological classification of atherosclerotic lesions: an update. Arterioscler Thromb Vasc Biol 2000;20:1177-1178.

142. Saam T, Cai J, Ma L, Cai YQ, Ferguson MS, Polissar NL, et al. Comparison of symptomatic and asymptomatic atherosclerotic carotid plaque features with in vivo MR imaging. Radiology 2006;240:464-472.

143. Freilinger TM, Schindler A, Schmidt C, Grimm J, Cyran C, Schwarz $F$, et al. Prevalence of nonstenosing, complicated atherosclerotic plaques in cryptogenic stroke. JACC Cardiovasc Imaging 2012;5:397-405.

144. Coutinho JM, Derkatch S, Potvin AR, Tomlinson G, Kiehl TR, Silver $\mathrm{FL}_{\mathrm{L}}$ et al. Nonstenotic carotid plaque on $\mathrm{CT}$ angiography in patients with cryptogenic stroke. Neurology 2016;87:665672.

145. Zhao X, Li R, Hippe DS, Hatsukami TS, Yuan C; CARE-II Investigators. Chinese Atherosclerosis Risk Evaluation (CARE II) study: a novel cross-sectional, multicentre study of the prevalence of high-risk atherosclerotic carotid plaque in Chinese patients with ischaemic cerebrovascular events-design and rationale. Stroke Vasc Neurol 2017;2:15-20.

146. Selwaness $M$, Hameeteman $R$, Van 't Klooster $R$, Van den Bouwhuijsen $\mathrm{Q}$, Hofman A, Franco $\mathrm{OH}$, et al. Determinants of carotid atherosclerotic plaque burden in a stroke-free population. Atherosclerosis 2016;255:186-192.

147. Palm F, Urbanek C, Wolf J, Buggle F, Kleemann T, Hennerici $M G$, et al. Etiology, risk factors and sex differences in ischemic stroke in the Ludwigshafen Stroke Study, a populationbased stroke registry. Cerebrovasc Dis 2012;33:69-75.

148. Bogiatzi C, Wannarong T, McLeod Al, Heisel M, Hackam D, Spence JD. SPARKLE (Subtypes of Ischaemic Stroke Classification System), incorporating measurement of carotid plaque burden: a new validated tool for the classification of ischemic stroke subtypes. Neuroepidemiology 2014;42:243251.

149. Spence JD, Eliasziw M, DiCicco M, Hackam DG, Galil R, Lohmann T. Carotid plaque area: a tool for targeting and evaluating vascular preventive therapy. Stroke 2002;33:2916-2922.

150. lemolo F, Martiniuk A, Steinman DA, Spence JD. Sex differences in carotid plaque and stenosis. Stroke 2004;35:477481.

151. Hyafil F, Schindler A, Sepp D, Obenhuber T, Bayer-Karpinska $A$, Boeckh-Behrens $T$, et al. High-risk plaque features can be detected in non-stenotic carotid plaques of patients with ischaemic stroke classified as cryptogenic using combined (18)F-FDG PET/MR imaging. Eur J Nucl Med Mol Imaging 2016;43:270-279.

152. Marquardt L, Kuker W, Chandratheva A, Geraghty O, Rothwell PM. Incidence and prognosis of $>$ or $=50 \%$ symptomatic vertebral or basilar artery stenosis: prospective population-based study. Brain 2009;132(Pt 4):982-988.

153. Al-Ali F, Barrow T, Duan L, Jefferson A, Louis S, Luke K, et al. Vertebral artery ostium atherosclerotic plaque as a potential source of posterior circulation ischemic stroke: result from borgess medical center vertebral artery ostium stenting registry. Stroke 2011;42:2544-2549.

154. Rozeman $A D$, Hund $H$, Westein $M$, Wermer MJH, Lycklama À Nijeholt GJ, et al. Duplex ultrasonography for the detection of vertebral artery stenosis: a comparison with CT angiography. Brain Behav 2017;7:e00750.

155. Khan S, Cloud GC, Kerry S, Markus HS. Imaging of vertebral artery stenosis: a systematic review. J Neurol Neurosurg Psychiatry 2007;78:1218-1225.

156. Coward U, McCabe DJ, Ederle J, Featherstone RL, Clifton $A$, Brown $\mathrm{MM}$, et al. Long-term outcome after angioplasty and stenting for symptomatic vertebral artery stenosis compared with medical treatment in the Carotid And Vertebral Artery Transluminal Angioplasty Study (CAVATAS): a randomized 
trial. Stroke 2007;38:1526-1530.

157. Compter A, van der Worp HB, Schonewille WJ, Vos JA, Boiten $J$, Nederkoorn PJ, et al. Stenting versus medical treatment in patients with symptomatic vertebral artery stenosis: a randomised open-label phase 2 trial. Lancet Neurol 2015;14:606614.

158. Markus HS, Larsson SC, Kuker W, Schulz UG, Ford I, Rothwell PM, et al. Stenting for symptomatic vertebral artery stenosis: The Vertebral Artery Ischaemia Stenting Trial. Neurology 2017;89:1229-1236.

159. Amin-Hanjani S, Du X, Rose-Finnell L, Pandey DK, Richardson $D$, Thulborn KR, et al. Hemodynamic features of symptomatic vertebrobasilar disease. Stroke 2015;46:1850-1856.

160. Amin-Hanjani S, Pandey DK, Rose-Finnell L, Du X, Richardson $D$, Thulborn KR, et al. Effect of hemodynamics on stroke risk in symptomatic atherosclerotic vertebrobasilar occlusive disease. JAMA Neurol 2016;73:178-185.

161. Amin-Hanjani $S$, Turan TN, Du X, Pandey DK, Rose-Finnell L, Richardson D, et al. Higher stroke risk with lower blood pressure in hemodynamic vertebrobasilar disease: analysis from the VERiTAS Study. J Stroke Cerebrovasc Dis 2017;26:403410.

162. Turan TN, Cotsonis G, Lynn MJ, Chaturvedi S, Chimowitz M; Warfarin-Aspirin Symptomatic Intracranial Disease (WASID) Trial Investigators. Relationship between blood pressure and stroke recurrence in patients with intracranial arterial stenosis. Circulation 2007;115:2969-2975.

163. Cohen A, Tzourio C, Bertrand B, Chauvel C, Bousser MG, Amarenco $P$. Aortic plaque morphology and vascular events: a follow-up study in patients with ischemic stroke. FAPS Investigators. French Study of Aortic Plaques in Stroke. Circulation 1997;96:3838-3841.

164. Amarenco P, Duyckaerts C, Tzourio C, Hénin D, Bousser MG, Hauw JJ. The prevalence of ulcerated plaques in the aortic arch in patients with stroke. N Engl J Med 1992;326:221-225.

165. Amarenco $P_{1}$ Cohen $A$, Tzourio $C$, Bertrand $B$, Hommel $M_{1}$ Besson $\mathrm{G}$, et al. Atherosclerotic disease of the aortic arch and the risk of ischemic stroke. N Engl J Med 1994;331:14741479.

166. Mitusch R, Doherty $C_{1}$ Wucherpfennig $H_{1}$ Memmesheimer $C_{1}$ Tepe C, Stierle U, et al. Vascular events during follow-up in patients with aortic arch atherosclerosis. Stroke 1997;28:36-39.

167. Rundek T, Di Tullio MR, Sciacca RR, Titova IV, Mohr JP, Homma $\mathrm{S}$, et al. Association between large aortic arch atheromas and high-intensity transient signals in elderly stroke patients. Stroke 1999;30:2683-2686.

168. Petty GW, Khandheria BK, Meissner I, Whisnant JP, Rocca WA, Sicks JD, et al. Population-based study of the relation- ship between atherosclerotic aortic debris and cerebrovascular ischemic events. Mayo Clin Proc 2006;81:609-614.

169. Meissner I, Khandheria BK, Sheps SG, Schwartz GL, Wiebers DO, Whisnant JP, et al. Atherosclerosis of the aorta: risk factor, risk marker, or innocent bystander? A prospective population-based transesophageal echocardiography study. J Am Coll Cardiol 2004;44:1018-1024.

170. Harloff A, Strecker C, Dudler P, Nussbaumer A, Frydrychowicz $A$, Olschewski $M$, et al. Retrograde embolism from the descending aorta: visualization by multidirectional 3D velocity mapping in cryptogenic stroke. Stroke 2009;40:1505-1508.

171. Harloff A, Simon J, Brendecke S, Assefa D, Helbing T, Frydrychowicz $A$, et al. Complex plaques in the proximal descending aorta: an underestimated embolic source of stroke. Stroke 2010;41:1145-1150.

172. Katsanos AH, Giannopoulos S, Kosmidou M, Voumvourakis K, Parissis JT, Kyritsis AP, et al. Complex atheromatous plaques in the descending aorta and the risk of stroke: a systematic review and meta-analysis. Stroke 2014;45:1764-1770.

173. Chatzikonstantinou $A$, Krissak R, Flüchter $S$, Artemis $D$, Schaefer A, Schoenberg SO, et al. CT angiography of the aorta is superior to transesophageal echocardiography for determining stroke subtypes in patients with cryptogenic ischemic stroke. Cerebrovasc Dis 2012;33:322-328.

174. Harloff A, Brendecke SM, Simon J, Assefa D, Wallis W,

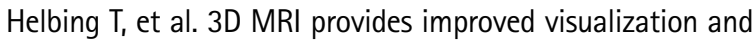
detection of aortic arch plaques compared to transesophageal echocardiography. J Magn Reson Imaging 2012;36:604611.

175. Wehrum T, Kams M, Strecker C, Dragonu I, Günther F, Geibel $A$, et al. Prevalence of potential retrograde embolization pathways in the proximal descending aorta in stroke patients and controls. Cerebrovasc Dis 2014;38:410-417.

176. Lima JA, Desai MY, Steen H, Warren WP, Gautam S, Lai S. Statin-induced cholesterol lowering and plaque regression after 6 months of magnetic resonance imaging-monitored therapy. Circulation 2004;110:2336-2341.

177. Tahara N, Kai $H$, Ishibashi $M$, Nakaura $H$, Kaida $H$, Baba $K$, et al. Simvastatin attenuates plaque inflammation: evaluation by fluorodeoxyglucose positron emission tomography. J Am Coll Cardiol 2006;48:1825-1831.

178. Mak W, Cheng TS, Chan KH, Cheung RT, Ho SL. A possible explanation for the racial difference in distribution of largearterial cerebrovascular disease: ancestral European settlers evolved genetic resistance to atherosclerosis, but confined to the intracranial arteries. Med Hypotheses 2005;65:637-648.

179. Jung KH, Lee SH, Kim BJ, Yu KH, Hong KS, Lee BC, et al. Secular trends in ischemic stroke characteristics in a rapidly de- 
veloped country: results from the Korean Stroke Registry Study (secular trends in Korean stroke). Circ Cardiovasc Qual Outcomes 2012;5:327-334.

180. Bang OY. Intracranial atherosclerosis: current understanding and perspectives. J Stroke 2014;16:27-35.

181. Gao S, Wong KS, Hansberg T, Lam WW, Droste DW, Ringelstein EB. Microembolic signal predicts recurrent cerebral ischemic events in acute stroke patients with middle cerebral artery stenosis. Stroke 2004;35:2832-2836.

182. Wu $X$, Zhang $H$, Liu $H$, Xing $Y$, Liu K. Microembolic signals detected with transcranial Doppler sonography differ between symptomatic and asymptomatic middle cerebral artery stenoses in Northeast China. PLoS One 2014;9:e88986.

183. Chimowitz MI, Lynn MJ, Howlett-Smith H, Stern BJ, Hertzberg VS, Frankel MR, et al. Comparison of warfarin and aspirin for symptomatic intracranial arterial stenosis. $N$ Engl J Med 2005;352:1305-1316.

184. Wang Y, Zhao X, Liu L, Soo YO, Pu Y, Pan Y, et al. Prevalence and outcomes of symptomatic intracranial large artery stenoses and occlusions in China: the Chinese Intracranial Atherosclerosis (CICAS) Study. Stroke 2014;45:663-669.

185. Caplan LR. Lacunar infarction and small vessel disease: pathology and pathophysiology. J Stroke 2015;17:2-6.

186. Yang WJ, Wong KS, Chen XY. Intracranial atherosclerosis: from microscopy to high-resolution magnetic resonance imaging. J Stroke 2017;19:249-260.

187. Yamamoto $Y$, Ohara $T$, Hamanaka $M$, Hosomi $A$, Tamura $A_{1}$ Akiguchi I. Characteristics of intracranial branch atheromatous disease and its association with progressive motor deficits. J Neuro/ Sci 2011;304:78-82.

188. Harteveld $A A$, van der Kolk $A G$, van der Worp HB, Dieleman $\mathrm{N}$, Siero JC, Kuijf HJ, et al. High-resolution intracranial vessel wall $\mathrm{MRI}$ in an elderly asymptomatic population: comparison of 3T and 7T. Eur Radiol 2017;27:1585-1595.

189. Harteveld AA, Denswil NP, Siero JC, Zwanenburg JJ, Vink A, Pouran $B$, et al. Quantitative intracranial atherosclerotic plaque characterization at 7T MRI: an ex vivo study with histologic validation. AJNR Am J Neuroradiol 2016;37:802810.

190. Chen XY, Wong KS, Lam WW, Zhao HL, Ng HK. Middle cerebral artery atherosclerosis: histological comparison between plaques associated with and not associated with infarct in a postmortem study. Cerebrovasc Dis 2008;25:74-80.

191. Xu WH, Li ML, Gao S, Ni J, Yao M, Zhou LX, et al. Middle cerebral artery intraplaque hemorrhage: prevalence and clinical relevance. Ann Neurol 2012;71:195-198.

192. Chimowitz MI, Lynn MJ, Derdeyn CP, Turan TN, Fiorella D, Lane $\mathrm{BF}$, et al. Stenting versus aggressive medical therapy for intra- cranial arterial stenosis. N Engl J Med 2011;365:993-1003.

193. Kern R, Steinke W, Daffertshofer M, Prager R, Hennerici M. Stroke recurrences in patients with symptomatic vs asymptomatic middle cerebral artery disease. Neurology 2005;65: 859-864.

194. Matsui R, Nakagawa T, Takayoshi $H$, Onoda K, Oguro $H_{1}$ Nagai $A$, et al. A prospective study of asymptomatic intracranial atherosclerotic stenosis in neurologically normal volunteers in a Japanese cohort. Front Neuro/2016;7:39.

195. Roth W, Morgello S, Goldman J, Mohr JP, Elkind MS, Marshall RS, et al. Histopathological differences between the anterior and posterior brain arteries as a function of aging. Stroke 2017;48:638-644.

196. Qureshi Al, Ziai WC, Yahia AM, Mohammad Y, Sen S, Agarwal $P$, et al. Stroke-free survival and its determinants in patients with symptomatic vertebrobasilar stenosis: a multicenter study. Neurosurgery 2003;52:1033-1039.

197. Kasner SE, Chimowitz MI, Lynn MJ, Howlett-Smith H, Stern BJ, Hertzberg VS, et al. Predictors of ischemic stroke in the territory of a symptomatic intracranial arterial stenosis. Circulation 2006;113:555-563.

198. Waddy SP, Cotsonis G, Lynn MJ, Frankel MR, Chaturvedi S, Williams $\mathrm{JE}_{\text {, }}$ et al. Racial differences in vascular risk factors and outcomes of patients with intracranial atherosclerotic arterial stenosis. Stroke 2009;40:719-725.

199. Wong KS, Huang YN, Gao S, Lam WW, Chan YL, Kay R. Intracranial stenosis in Chinese patients with acute stroke. Neurology 1998;50:812-813.

200. Arenillas JF, Molina CA, Montaner J, Abilleira S, GonzálezSánchez MA, Alvarez-Sabín J. Progression and clinical recurrence of symptomatic middle cerebral artery stenosis: a long-term follow-up transcranial Doppler ultrasound study. Stroke $2001 ; 32: 2898-2904$.

201. Leng $X$, Scalzo $F$, Ip HL, Johnson $M$, Fong AK, Fan FS, et al. Computational fluid dynamics modeling of symptomatic intracranial atherosclerosis may predict risk of stroke recurrence. PLoS One 2014;9:e97531.

202. Hoshino T, Sissani L, Labreuche J, Ducrocq G, Lavallée PC, Meseguer $E_{\text {, et }}$ al. Prevalence of systemic atherosclerosis burdens and overlapping stroke etiologies and their associations with long-term vascular prognosis in stroke with intracranial atherosclerotic disease. JAMA Neurol 2018;75:203211.

203. Liebeskind DS, Cotsonis GA, Saver JL, Lynn MJ, Turan TN, Cloft $\mathrm{HJ}$, et al. Collaterals dramatically alter stroke risk in intracranial atherosclerosis. Ann Neurol 2011;69:963-974.

204. Lau AY, Wong EH, Wong A, Mok VC, Leung TW, Wong KS. Significance of good collateral compensation in symptomatic 
intracranial atherosclerosis. Cerebrovasc Dis 2012;33:517524.

205. Waters MF, Hoh BL, Lynn MJ, Kwon HM, Turan TN, Derdeyn $\mathrm{CP}$, et al. Factors associated with recurrent ischemic stroke in the medical group of the SAMMPRIS trial. JAMA Neurol 2016;73:308-315.

206. Kim BS, Chung PW, Park KY, Won HH, Bang OY, Chung CS, et al. Burden of intracranial atherosclerosis is associated with long-term vascular outcome in patients with ischemic stroke. Stroke 2017;48:2819-2826.

207. Jung JM, Kang DW, Yu KH, Koo JS, Lee JH, Park JM, et al. Predictors of recurrent stroke in patients with symptomatic intracranial arterial stenosis. Stroke 2012;43:2785-2787.

208. Ovbiagele B, Saver JL, Lynn MJ, Chimowitz M; WASID Study Group. Impact of metabolic syndrome on prognosis of symptomatic intracranial atherostenosis. Neurology 2006;66:13441349.

209. Wang $X$, Lin WH, Zhao YD, Chen XY, Leung TW, Chen $C$, et al. The effectiveness of dual antiplatelet treatment in acute ischemic stroke patients with intracranial arterial stenosis: a subgroup analysis of CLAIR study. Int J Stroke 2013;8:663-668.
210. Sangha RS, Naidech AM, Corado C, Ansari SA, Prabhakaran S. Challenges in the medical management of symptomatic intracranial stenosis in an urban setting. Stroke 2017;48:21582163.

211. Liu L, Wong KS, Leng $X, P u Y$, Wang $Y$, Jing J, et al. Dual antiplatelet therapy in stroke and ICAS: subgroup analysis of CHANCE. Neurology 2015;85:1154-1162.

212. Tsivgoulis G, Katsanos AH, Magoufis G, Kargiotis O, Papadimitropoulos G, Vadikolias $K$, et al. Percutaneous transluminal angioplasty and stenting for symptomatic intracranial arterial stenosis: a systematic review and meta-analysis. Ther Adv Neurol Disord 2016;9:351-358.

213. Fiorella D, Derdeyn CP, Lynn MJ, Barnwell SL, Hoh BL, Levy El, et al. Detailed analysis of periprocedural strokes in patients undergoing intracranial stenting in Stenting and Aggressive Medical Management for Preventing Recurrent Stroke in Intracranial Stenosis (SAMMPRIS). Stroke 2012;43:2682-2688.

214. Gao P, Zhao Z, Wang D, Wu J, Cai Y, Li T, et al. China Angioplasty and Stenting for Symptomatic Intracranial Severe Stenosis (CASSISS): a new, prospective, multicenter, randomized controlled trial in China. Interv Neuroradio/ 2015;21:196-204. 